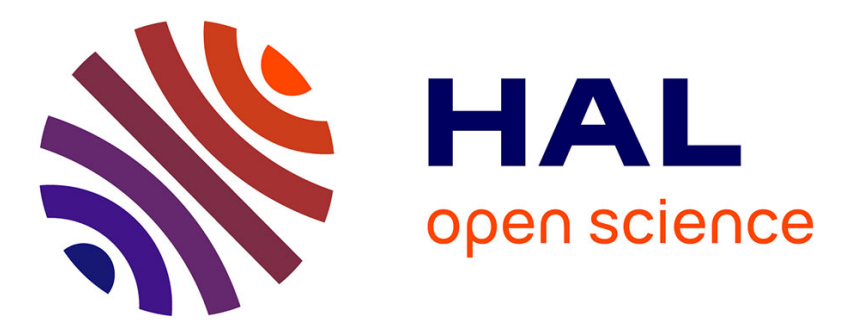

\title{
Processes influencing ozone levels in Alaskan forest fire plumes during long-range transport over the North Atlantic
}

Elsa Real, Kathy S. Law, Bernadett Weinzierl, M. Fiebig, A. Petzold, O. Wild, J. Methven, S. Arnold, A. Stohl, H. Huntrieser, et al.

\section{To cite this version:}

Elsa Real, Kathy S. Law, Bernadett Weinzierl, M. Fiebig, A. Petzold, et al.. Processes influencing ozone levels in Alaskan forest fire plumes during long-range transport over the North Atlantic. Journal of Geophysical Research: Atmospheres, 2007, 112, pp.D10S41. 10.1029/2006JD007576 . hal00164294

\section{HAL Id: hal-00164294 \\ https://hal.science/hal-00164294}

Submitted on 14 Nov 2016

HAL is a multi-disciplinary open access archive for the deposit and dissemination of scientific research documents, whether they are published or not. The documents may come from teaching and research institutions in France or abroad, or from public or private research centers.
L'archive ouverte pluridisciplinaire HAL, est destinée au dépôt et à la diffusion de documents scientifiques de niveau recherche, publiés ou non, émanant des établissements d'enseignement et de recherche français ou étrangers, des laboratoires publics ou privés. 


\title{
Processes influencing ozone levels in Alaskan forest fire plumes during long-range transport over the North Atlantic
}

\author{
E. Real, ${ }^{1}$ K. S. Law, ${ }^{1}$ B. Weinzierl, ${ }^{2}$ M. Fiebig, ${ }^{2}$ A. Petzold, ${ }^{2}$ O. Wild, ${ }^{3}$ J. Methven, ${ }^{4}$ \\ S. Arnold, ${ }^{5}$ A. Stohl, ${ }^{6}$ H. Huntrieser, ${ }^{2}$ A. Roiger, ${ }^{2}$ H. Schlager, ${ }^{2}$ D. Stewart, ${ }^{7}$ M. Avery, ${ }^{8}$ \\ G. Sachse, ${ }^{8}$ E. Browell, ${ }^{8}$ R. Ferrare, ${ }^{8}$ and D. Blake ${ }^{9}$ \\ Received 31 May 2006; revised 19 October 2006; accepted 4 January 2007; published 8 May 2007.
}

[1] A case of long-range transport of a biomass burning plume from Alaska to Europe is analyzed using a Lagrangian approach. This plume was sampled several times in the free troposphere over North America, the North Atlantic and Europe by three different aircraft during the IGAC Lagrangian 2K4 experiment which was part of the ICARTT/ ITOP measurement intensive in summer 2004. Measurements in the plume showed enhanced values of $\mathrm{CO}$, VOCs and $\mathrm{NO}_{y}$, mainly in form of PAN. Observed $\mathrm{O}_{3}$ levels increased by 17 ppbv over 5 days. A photochemical trajectory model, CiTTyCAT, was used to examine processes responsible for the chemical evolution of the plume. The model was initialized with upwind data and compared with downwind measurements. The influence of high aerosol loading on photolysis rates in the plume was investigated using in situ aerosol measurements in the plume and lidar retrievals of optical depth as input into a photolysis code (Fast-J), run in the model. Significant impacts on photochemistry are found with a decrease of $18 \%$ in $\mathrm{O}_{3}$ production and $24 \%$ in $\mathrm{O}_{3}$ destruction over 5 days when including aerosols. The plume is found to be chemically active with large $\mathrm{O}_{3}$ increases attributed primarily to PAN decomposition during descent of the plume toward Europe. The predicted $\mathrm{O}_{3}$ changes are very dependent on temperature changes during transport and also on water vapor levels in the lower troposphere which can lead to $\mathrm{O}_{3}$ destruction. Simulation of mixing/dilution was necessary to reproduce observed pollutant levels in the plume. Mixing was simulated using background concentrations from measurements in air masses in close proximity to the plume, and mixing timescales (averaging 6.25 days) were derived from $\mathrm{CO}$ changes. Observed and simulated $\mathrm{O}_{3} / \mathrm{CO}$ correlations in the plume were also compared in order to evaluate the photochemistry in the model. Observed slopes change from negative to positive over 5 days. This change, which can be attributed largely to photochemistry, is well reproduced by multiple model runs even if slope values are slightly underestimated suggesting a small underestimation in modeled photochemical $\mathrm{O}_{3}$ production. The possible impact of this biomass burning plume on $\mathrm{O}_{3}$ levels in the European boundary layer was also examined by running the model for a further 5 days and comparing with data collected at surface sites, such as Jungfraujoch, which showed small $\mathrm{O}_{3}$ increases and elevated $\mathrm{CO}$ levels. The model predicts significant changes in $\mathrm{O}_{3}$ over the entire 10 day period due to photochemistry but the signal is largely lost because of the effects of dilution. However, measurements in several other BB plumes over Europe show that $\mathrm{O}_{3}$ impact of Alaskan fires can be potentially significant over Europe.

Citation: Real, E., et al. (2007), Processes influencing ozone levels in Alaskan forest fire plumes during long-range transport over the North Atlantic, J. Geophys. Res., 112, D10S41, doi:10.1029/2006JD007576.

\footnotetext{
${ }^{1}$ Service d'Aéronomie du CNRS, Institut Pierre-Simon Laplace, Université Pierre et Marie Curie, Paris, France.

${ }^{2}$ Institut für Physik der Atmosphäre, Deutsches Zentrum für Luft- und Raumfahrt, Wessling, Germany.

${ }^{3}$ Centre for Atmospheric Science, Department of Chemistry, University of Cambridge, Cambridge, UK.

Copyright 2007 by the American Geophysical Union. 0148-0227/07/2006JD007576
}

\footnotetext{
${ }^{4}$ Department of Meteorology, University of Reading, Reading, UK. ${ }^{5}$ School of Earth and Environment, University of Leeds, Leeds, UK. ${ }^{6}$ Norwegian Institute for Air Research, Kjeller, Norway. UK.

${ }^{7}$ School of Environmental Science, University of East Anglia, Norwich, ${ }^{8}$ Atmospheric Science Division, NASA Langley Research Center, Hampton, Virginia, USA. USA.

${ }^{9}$ Department of Chemistry, University of California, Irvine, California,
} 


\section{Introduction}

[2] There is a large body of evidence that pollutants can be transported from source regions to remote areas, and thus can influence the oxidizing capacity over downwind regions, and occasionally regional air quality thousands of kilometers away from emissions. During export from emission regions, polluted plumes undergo chemical evolution and mixing with air masses of different origin so that their chemical composition can radically change. Ozone levels in such polluted plumes are of particular interest since $\mathrm{O}_{3}$ is a major pollutant, damaging for health but also the major source of the $\mathrm{OH}$ radical, and the most efficient cleansing agent in the atmosphere. $\mathrm{O}_{3}$ is mainly produced by reactions involving oxidation of volatile organic compounds (VOCs), and carbon monoxide $(\mathrm{CO})$ in the presence of nitrogen oxides $\left(\mathrm{NO}_{x}=\mathrm{NO}+\mathrm{NO}_{2}\right)$, and mainly destroyed by reactions involving $\mathrm{H}_{2} \mathrm{O}$ and $\mathrm{HO}_{x}$ radicals.

[3] $\mathrm{O}_{3}$ evolution in anthropogenic pollution plumes transported over long distances has been widely studied [Wild and Akimoto, 2001; Jacob et al., 1999] but less is known about $\mathrm{O}_{3}$ formation in biomass burning plumes, especially those in boreal regions. Biomass burning (BB) has been recognized as an important source of many trace gases and particles [Crutzen et al., 1979; Crutzen and Andreae, 1990] including $\mathrm{CO}, \mathrm{CO}_{2}, \mathrm{CH}_{4}$, VOCs, oxygenated organic compounds and $\mathrm{NO}_{x}$. BB emissions occur most extensively in tropical and subtropical regions with the largest contributions from Africa and South America, and smaller contributions from southeast Asia, Indonesia and Australia [Galanter et al., 2000]. Boreal forest fires in North America and Russia are less frequent, but important in summer time in certain years [Stohl et al., 2006]. Long-range transport of BB plumes has been previously observed during several campaigns. For example, African BB plumes were sampled over the tropical south Atlantic [Andreae et al., 1994] and over Australia [Pak et al., 2003], southeast Asian BB plumes were sampled over the west Pacific [Kondo et al., 2004] while Canadian BB plumes have been sampled over Tennessee (United States) [Wotawa and Trainer, 2000; McKeen et al., 2002] and also at the surface station Mace Head (Ireland) [Forster et al., 2001]. All these plumes showed enhanced $\mathrm{CO}$ correlated with enhanced $\mathrm{O}_{3}$. Modeling studies of BB plumes (either with box models or global models) also often show net $\mathrm{O}_{3}$ production in such plumes [Mauzerall et al., 1998; Duncan et al., 2003; Tang et al., 2003].

[4] The International Global Atmospheric Chemistry (IGAC) Lagrangian 2K4 experiment was conducted in summer 2004 over the North Atlantic as part of ICARTT [Fehsenfeld et al., 2006], also encompassing the European Intercontinental Transport of Ozone and Precursors (ITOP) experiment. The aim of this experiment was to perform a Lagrangian study of polluted air masses, making interceptions several times using 4 different research aircraft during their transport from North America to Europe. Lagrangian experiments have been conducted previously, for example, in the stratosphere [Rex et al., 1998] using balloons, or close to emission regions [Daum et al., 2000; Volz-Thomas and Kolahgar, 2000]. This is the first time that a Lagrangian experiment has been conducted in the free troposphere on intercontinental scales. The main advantage of this kind of study is that the exact chemical change in a plume over several days can be estimated by comparing two Lagrangian samplings, and the processes leading to these changes can be evaluated with reduced uncertainty in the initial chemical composition of the plume. After the campaign a detailed analysis using trajectories, a Lagrangian dispersion model, and in situ measurements was performed by Methven et al. [2006], and showed that several Lagrangian samplings of the same air masses had indeed been achieved. The period of the campaign was characterized by extensive fires in Alaska (the largest on record), and northern Canada [Damoah et al., 2006; Stohl et al., 2006]. The quantity of $\mathrm{CO}$ released during this period is believed to be of the same order as anthropogenic emissions from the entire continental United States for the same period [Pfister et al., 2005; Turquety et al., 2007]. CO enhancements due to these fires were observed together with aerosol, and trace gas enhancements in the Arctic [Stohl et al., 2006], in North America, both in the boundary layer (BL) and the free troposphere (FT) over Chebogue Point (Nova Scotia) [Duck et al., 2007], and Texas [Morris et al., 2006], in the lower free troposphere over the Atlantic Ocean [Val Martin et al., 2006], and in the FT over Europe [Petzold et al., 2007; Ravetta et al., 2007]. Deep convection associated with these fires (so-called pyroconvection) may have also led to injection of BB plumes into the upper troposphere (UT), and even into the lower stratosphere (LS) [Damoah et al., 2006].

[5] In the study reported here, we focus on one particular case of the transport of a BB plume over the North Atlantic that was sampled by 3 different aircraft over a period of 5 days (section 2). To evaluate the relative contributions of chemical and dynamical processes to the evolution of $\mathrm{O}_{3}$ concentrations in the plume during transport, a photochemical trajectory model has been used (section 3). BB plumes are also characterized by high aerosol loadings, and therefore the model was improved to include the effects of BB aerosols on photolysis rates by making use of measured parameters to estimate aerosol optical properties (section 4). This is the first time, to our knowledge, that measured parameters have been used to constrain photolysis rate calculations over intercontinental distances. In section 5, results are presented from model runs initialized with upwind data, and compared to downwind measurements. The model was run along one trajectory representative of the plume transport pathway, and which gave the best match between plume samplings. The model was run first with chemistry only, and then including mixing with air masses in close proximity to the plume. The ability of the model to reproduce the contribution of photochemistry to $\mathrm{O}_{3}$ changes in the plume, was further tested in section 6 , by examining the evolution of $\mathrm{O}_{3} / \mathrm{CO}$ correlations. Model runs initialized with measurements taken across the plume sampling were compared to downwind $\mathrm{O}_{3}: \mathrm{CO}$ ratios. Finally, we examine other available data collected downwind over Europe in order to see if a signal of this BB event could be detected. Further model runs were used to estimate the overall change in $\mathrm{O}_{3}$ concentrations since the upwind sampling 10 days earlier (section 7). Whilst the results presented here are for one particular event, such detailed Lagrangian studies are very valuable since they allow direct 


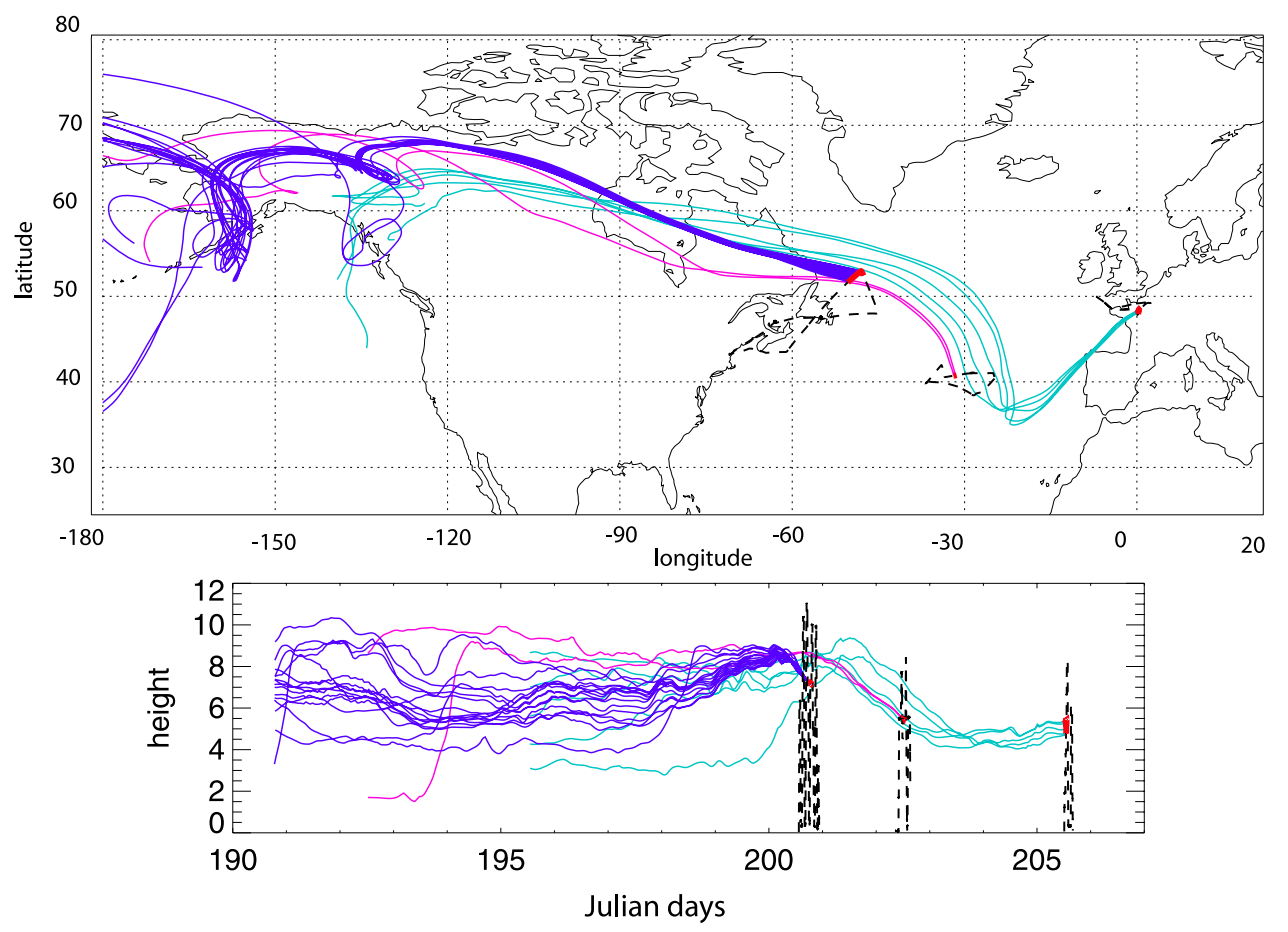

Figure 1. Flight tracks of the DC8 (18 July), the BAe146 (20 July) and the Falcon (23 July) (black lines). Lagrangian matches along the flights are represented in red together with FLEXTRA backward trajectories from these matches (blue-green for the Falcon, pink for the BAe-146 and blue-violet for the DC8).

evaluation of processes occurring in a plume during longrange transport.

\section{Lagrangian Forest Fire Plume Case}

[6] Methven et al. [2006] used a novel technique to identify Lagrangian matches between flight segments from different aircraft during the entire IGAC Lagrangian $2 \mathrm{~K} 4$ campaign. This technique combined Lagrangian trajectories from the United Kingdom Global Atmospheric Modeling Project (UGAMP) model, hydrocarbon fingerprint analysis, and results from a particle dispersion model (FLEXPART). A match was defined as an occasion when a pair of whole air samples collected during different flights exhibited highly correlated hydrocarbon fingerprints (when such measurements were available), and the sample-time windows were also connected by both backward and forward trajectories. Results from FLEXPART run with CO tracers were also used to confirm matches. Five clear Lagrangian cases covering a variety of situations, such as low and upper level export of pollutants from North America, and longrange transport of $\mathrm{BB}$ plumes from Alaska and Canada over the North Atlantic to Europe, were identified. An important consideration is whether instrument errors can lead to observed differences between samplings. Intercomparison flights between the different aircraft showed good agreements for $\mathrm{O}_{3}$, and differences of a few ppbv for CO. Further details, as well as a critical evaluation of this Lagrangian technique, are given by Methven et al. [2006].

[7] In this paper, we focus on one of these Lagrangian cases, the case of long-range transport of an intense BB plume sampled over 5 days first by the National Aeronau- tics and Space Administration (NASA) DC8 over Newfoundland on 18 July, then by the United Kingdom Facility for Airborne Atmospheric Measurements (FAAM) BAe146 flying out of the Azores on 20 July, and lastly the German Deutsches Zentrum für Luft- und Raumfahrt (DLR) Falcon flying west of Paris on 23 July. The British and German aircraft were flying as part of the European ITOP project. The segments of the three flights identified as Lagrangian matches were labeled as Lagrangian case 2 by Methven et al. [2006].

[8] Backward trajectories from the match segments of the 3 flights clearly show that the sampled plume had an origin in northern Canada and Alaska (see Figure 1) where forest fires were burning during this period [Pfister et al., 2005]. The FLEXPART model, run with daily $\mathrm{CO}$ forest fire emissions from Canada/Alaska, showed that BB plumes observed during the campaign were usually an accumulation of biomass burning emissions over several days which were then transported into the free troposphere either by frontal uplift or convection [Stohl et al., 2006]. In this case, FLEXPART results show that the pollutants sampled by the aircraft were primarily emitted by fires on 14 and 15 July (see FLEXPART products at http://esrl.noaa.gov/csd/ ICARTT/analysis/).

[9] In this study, a photochemical trajectory model has been used to analyze observed $\mathrm{O}_{3}$ changes. Therefore it was necessary to select a trajectory representative of the plume pathway between the upwind DC8 segment (used to initialize the runs), passing via the BAe146 match, and ending at the Falcon match. Trajectories from the FLEXTRA model [Stohl et al., 1995] were used here, but it should noted that differences between trajectories from this model, and those 
Table 1. Measurements Taken During Lagrangian Match Windows Defined by Methven et al. [2006, Table 1] ${ }^{\mathrm{a}}$

\begin{tabular}{|c|c|c|c|}
\hline & $\begin{array}{c}\text { DC8 Lagrangian } \\
\text { Sampling }(24 \mathrm{mn})\end{array}$ & $\begin{array}{l}\text { BAe146 Lagrangian } \\
\text { Sampling ( } 5 \mathrm{mn})\end{array}$ & $\begin{array}{l}\text { Falcon Lagrangian } \\
\text { Sampling (14 mn) }\end{array}$ \\
\hline Species & $440(68)$ [129] & $414(53)[300]$ & $244(35)[840]$ \\
\hline $\mathrm{O}_{3}, \mathrm{ppbv}$ & $61.6(2.6)[133]$ & $67.3(1.2)[300]$ & 79 (3.6) [840] \\
\hline NO, pptv & 115 (65) [105] & 49 (16) [45] & 29 (6) [840] \\
\hline $\mathrm{NO}_{2}, \mathrm{pptv}$ & $28(10)[105]$ & & \\
\hline PAN, pptv & $1842^{\mathrm{b}}(140)[30]$ & 2727 (197) [300] & \\
\hline $\mathrm{HNO}_{3}$, pptv & $84(10)[87]$ & & \\
\hline $\mathrm{NO}_{y}, \mathrm{pptv}$ & & & $1956(243)$ [840] \\
\hline $\mathrm{C}_{2} \mathrm{H}_{4}, \mathrm{pptv}$ & $2156(360)[20]$ & 1123 (371) [131] & \\
\hline $\mathrm{C}_{2} \mathrm{H}_{6}, \mathrm{pptv}$ & $3595(475)[20]$ & $4030(371)[131]$ & \\
\hline $\mathrm{C}_{2} \mathrm{H}_{2}$, pptv & $1365(169)[20]$ & $1123(132)[131]$ & \\
\hline $\mathrm{C}_{3} \mathrm{H}_{8}, \mathrm{pptv}$ & 790 (132) [20] & & \\
\hline $\mathrm{C}_{3} \mathrm{H}_{6}, \mathrm{pptv}$ & $84(20)[20]$ & & \\
\hline $\mathrm{C}_{4} \mathrm{H}_{8}, \mathrm{pptv}$ & 12 (3) $[20]$ & & \\
\hline $\mathrm{C}_{4} \mathrm{H}_{10}, \mathrm{pptv}$ & $220(40)[20]$ & $82(9)$ [131] & \\
\hline $\mathrm{C}_{5} \mathrm{H}_{8}, \mathrm{pptv}$ & $4(0.8)[20]$ & & \\
\hline $\mathrm{C}_{5} \mathrm{H}_{12}, \mathrm{pptv}$ & 70 (14) [20] & & \\
\hline $\mathrm{C}_{6} \mathrm{H}_{6}, \mathrm{pptv}$ & $710(128)[20]$ & $858(64)[131]$ & \\
\hline $\mathrm{C}_{7} \mathrm{H}_{8}, \mathrm{pptv}$ & $51(15)[20]$ & $133(17)[131]$ & \\
\hline Temp, K & $247(0.2)[133]$ & $266(0.06)[300]$ & 273 (2) [131] \\
\hline $\mathrm{H}_{2} \mathrm{O}, \mathrm{g} / \mathrm{kg}$ & $0.24(0.04)[133]$ & $0.29(0.01)[300]$ & $1.9(0.4)[131]$ \\
\hline
\end{tabular}

aData for each window are shown as "mean (standard deviation) [number of measurements averaged]."

${ }^{\mathrm{b}} \mathrm{PAN}$ is not measured during the larger part of the DC8 match.

calculated by Methven et al. [2006] are small since they used the same wind fields (European Centre for Mediumrange Weather Forecast (ECMWF) ERA 40 analyzes), and for this particular case, the models produce the same features.

[10] As noted previously, Methven et al. [2006] used a combination of forward, and backward trajectories, trace gas and VOC analysis, and FLEXPART results to match up plume segments. Use of trajectories alone shows some differences. For example, forward trajectories from the DC8 flight segment arrive around $1 \mathrm{~km}$ lower than the Falcon match segment. Specific humidity, taken from ECMWF, is also a factor of 2 wetter. Conversely, backward trajectories from the Falcon segment are about $1 \mathrm{~km}$ above the DC8 match, and the analysis temperature slightly colder. Errors of this nature are inherent in trajectory calculations (Stohl [1998] gave positioning errors on the order of $20 \%$ of the travel distances). Runs along both backward and forward trajectories, and also examination of the sensitivity of $\mathrm{O}_{3}$ change to temperature and water vapor (see section 5.2) led us to use a backward trajectory from the Falcon plume match segment which gave the best agreement with observed meteorological variables.

[11] The chemical evolution of the plume can be investigated first by examining the differences in the chemical data averaged over the time match windows (see Table 1 and Methven et al. [2006, Table 1]). Pollutant levels measured by the $\mathrm{DC} 8$ were representative of the chemical composition of the BB plume 3 to 4 days after emission. By this time, $\mathrm{CO}$ values measured by the $\mathrm{DC} 8$, at a mean altitude of $7.5 \mathrm{~km}$, were still exceptionally high with a mean value of $449 \mathrm{ppbv}$, and maximum values up to $600 \mathrm{ppbv}$ (see Figure 2) which correlated with high values of several hydrocarbons such as ethene, ethane and acetylene. $\mathrm{NO}_{y}$ was mainly in the form of PAN with relatively low levels of $\mathrm{HNO}_{3}$ and $\mathrm{NO}_{x}$ observed in the plume. Unfortunately PAN was only measured at the beginning of the plume sampling (plume edge) by the DC8, and so is not representative of plume values which are likely to have been higher in the plume center.

[12] $\mathrm{O}_{3}$ levels in the plume were rather low (mean value of $62 \mathrm{ppbv}$ ) compared to values outside the plume. However, Pfister et al. [2006] simulated background $\mathrm{O}_{3}$ levels lower than 40 ppbv over the Alaskan source region during summer 2004 with a global model. Very low background (non-fire-affected) values (20 to $30 \mathrm{ppbv}$ ) have also been measured previously in this region during ABLE-3A [Harriss et al., 1992], so that the mean value of $62 \mathrm{ppbv}$ observed 4 days later by the DC8 may indicate that $\mathrm{O}_{3}$ production has in fact taken place although in situ measurements in the emission region would be needed to confirm this. Interestingly, $\mathrm{O}_{3}$ and $\mathrm{CO}$ were anticorrelated in the DC8 plume (see section 6 for further discussion).

[13] By the time the BAe146 sampled the plume 2 days later, $\mathrm{CO}$ had decreased by about $30 \mathrm{ppbv}$, and by the time it was sampled by the DLR Falcon southwest of Paris, 3 days later, $\mathrm{CO}$ had decreased to half the levels seen by the DC8. In contrast, $\mathrm{O}_{3}$ levels had increased by 17 ppbv over 5 days between the different samplings. In this study, we aim to explain this $\mathrm{O}_{3}$ increase. It is also interesting to examine whether a plume like this with elevated $\mathrm{O}_{3}$ can have an impact on $\mathrm{O}_{3}$ levels in the lower troposphere or boundary layer over Europe. This is investigated in section 7.

\section{Modeling Tools}

[14] The Cambridge Tropospheric Trajectory model of Chemistry and Transport (CiTTyCAT) was used to examine the different processes influencing the evolution of trace gases within the plume during transport, and in particular the evolution of $\mathrm{O}_{3}$ and CO. CiTTyCAT was initialized with measured values in the upwind plume on $18 \mathrm{July}$, and run along the trajectory representative of the plume pathway.

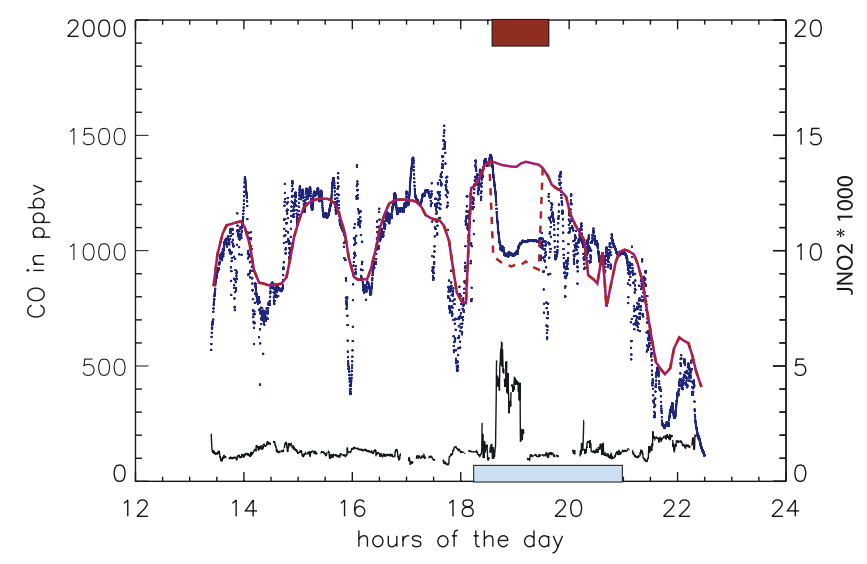

Figure 2. $\mathrm{DC} 8$ measured $\mathrm{CO}$ mixing ratio (black line) and $\mathrm{jNO}_{2}$ (blue dashed line) together with simulated $\mathrm{jNO}_{2}$ along the flight with (pink dashed line) and without (pink solid line) aerosols. For both simulations, a low cloud layer was simulated at the blue rectangle location. For the simulation including aerosols, the simulated aerosol layer was collocated with the $\mathrm{BB}$ plume (indicated by the red rectangle). The largest $\mathrm{jNO}_{2}$ variations are due to change in the altitude of the aircraft (see flight altitude shown in Figure 3). 
Results from the model were then compared with downwind measurements taken in the matching flight segments of the BAe146 and Falcon flights, 2 and 5 days later. In order to take into account the influence of BB aerosols on photolysis rates, the CiTTyCAT model was coupled with the Fast-J photolysis scheme [Wild et al., 2000] which can calculate photolysis rates in the presence of aerosols.

\subsection{Photochemistry Trajectory Model: CiTTyCAT}

[15] CiTTyCAT has been used previously to examine the origin of polluted layers over the North Atlantic [Wild et al., 1996; Evans et al., 2000]. The model is considered as an isolated air parcel, and run along trajectories calculated using large-scale meteorological analyzes. Eighty-eight chemical species are treated in the model including degradation of 12 hydrocarbons using chemical rate data from JPL (2003), and updates discussed in Arnold et al. [2007]. The photolysis scheme normally used in the model is based on a 2-stream multiple scattering scheme [Hough, 1988]. Emissions and dry deposition can be included in the boundary layer as well as wet deposition in the presence of clouds. A scheme for mixing with other air masses can also be included. As discussed previously, the model was run along a trajectory calculated by the FLEXTRA model using ECMWF windfields. Temperature and water vapor used in the chemical scheme were also interpolated from the largescale ECMWF analyzes along the trajectory. In this study, the possible effects of heterogeneous reactions on $\mathrm{BB}$ aerosol have not be taken into account. At present, the impacts of such reactions on this kind of aerosol, consisting primarily of organics, is very uncertain. L. K. Whalley et al. (personal communication, 2007), who also examined this case, attempted to take this into account by including the loss of $\mathrm{N}_{2} \mathrm{O}_{5}$ on $\mathrm{BB}$ aerosol with a $\gamma$ of 0.02 as suggested by work from Evans and Jacob [2005]. They found a $20 \%$ reduction in $\mathrm{NO}_{x}$ concentrations over the first 24 hours which resulted in negligible $\mathrm{O}_{3}$ changes compared to runs without heterogeneous loss. Wet deposition processes are not considered here as aerosol measurements on board the Falcon as well as ECMWF analyzed cloud fields suggest that the plume did not pass through any clouds.

[16] Table 1 gives the mean plus/minus the standard deviation of all the measurements collected by the aircraft used in the model initialization (DC8 data, except PAN) and comparison (BAe146 and DLR Falcon data). The total number of measurements used to calculate these values in the match segments is also given. As explained in section 2, PAN measurements were missing during the main part of the DC8 match so the measured PAN/CO correlation during the BAe146 match was used to estimate initial PAN values. This correlation was scaled by measured DC8 CO as also discussed by L. Whalley et al. (personal communication, 2007) giving a mean PAN value of 2800 pptv together with a 400 pptv standard deviation. This assumes that PAN and CO do not change much chemically between the two matches. Indeed, as will be seen in section 5.2, simulated $\mathrm{CO}$ and PAN only decrease, because of chemistry, by 20 ppbv and 200 pptv between the DC8 and BAe146 matches, respectively, producing only a small impact on the PAN/CO correlation.

\subsection{Photolysis Scheme: Fast-J}

[17] The Fast-J scheme calculates photolysis rates (j-values) in the presence of prescribed cloud and aerosol layers [Wild et al., 2000] making it possible to simulate directly the physical properties of scattering and absorbing particles including the full, untruncated scattering phase function and the total optical depth. For the case under investigation, aerosol optical properties (AOPs) were derived from Falcon measurements in the BB plume. BB optical depths (ODs) used in the code were calculated from a combination of DC8 and Falcon retrievals for 18 and 23 July as discussed in the next section. The original 2-stream photolysis scheme in CiTTyCAT uses 171 wavelength intervals in the short-wave whereas Fast-J solves the 8 -stream multiple scattering problem by using only 7 wavelength bins selected in the range $289-850 \mathrm{~nm}$ to minimize errors in key $\mathrm{j}$-values over a range of atmospheric conditions. Values of $\mathrm{jNO}_{2}$ and $\mathrm{jO}_{3}$ (i.e., that producing $\mathrm{O}^{1} \mathrm{D}$ ) calculated using the two codes run in CiTTyCAT with no clouds or aerosols, were comparable to within $1 \%$. In runs with no aerosols or clouds discussed in the following sections, a simple profile of absorbing black carbon uniformly distributed from the surface to $10 \mathrm{~km}$ with an optical depth of 0.001 was included to represent relatively clean conditions.

\section{Aerosol Measurements and Optical Properties}

[18] BB aerosols consist mainly of black carbon (BC), organic carbon $(\mathrm{OC})$ and potassium. It is the $\mathrm{BC}$ component which acts as a strong light absorbent. Sampling obtained during the campaign in a BB layer on board the BAe146 showed that these aerosols were principally made of organic and black carbon with the organic fraction dominating (H. Coe, personal communication, 2006). In the plume considered here, analysis by Petzold et al. [2007] suggests a $\mathrm{BC}$ fraction of $3.8 \%$ by volume compared to typical $\mathrm{BC}$ mass fractions in temperate/boreal fires on the order of 2 to 7\% [Reid et al., 2004].

[19] Previous studies have shown that BB aerosols can significantly decrease photolysis rates, and thereby influence $\mathrm{O}_{3}$ evolution in $\mathrm{BB}$ plumes [Tang et al., 2003; Trentmann et al., 2003; Duncan et al., 2003]. However, their impact depends strongly on AOPs and aerosol concentration. BB aerosol AOPs can vary significantly depending on the age of the aerosols, the mode of combustion of the fire (smoldering or flaming), the combustion efficiency, and the combustible material [Reid et al., 2005]. Optical properties of $\mathrm{BB}$ aerosols which are wavelength dependent or their absorption properties can be very different from one fire to another. For example, aerosols from temperate and boreal fires often have higher values of the single scattering albedo than aerosols from tropical fires. Indeed, a realistic evaluation of the influence of BB aerosols on photolysis rates requires a good evaluation of the AOPs from particular fire events.

[20] In situ measurements of BB aerosol characteristics have been used previously to simulate aerosol impacts on photolysis rates, and thus on photochemistry, in the initial 
Table 2. Parameters of the Three Lognormal Distribution Functions Fitted to the DLR Falcon Aerosol Measurements ${ }^{\mathrm{a}}$

\begin{tabular}{lccc}
\hline & $\mathrm{N}, \mathrm{part} / \mathrm{cm}^{3}$ & $\mathrm{r}_{m}$, micrometer & $\sigma_{g}$ \\
\hline Mode 1 & 1400 & 0.037 & 1.6 \\
Mode 2 & 1100 & 0.125 & 1.3 \\
Mode 3 & 15 & 0.175 & 1.8 \\
\hline
\end{tabular}

${ }^{\mathrm{a}} \mathrm{N}$ is the integral particle number concentration in part $/ \mathrm{cm}^{3}, \mathrm{r}_{m}$ is the particle median radius in micrometer and $\sigma_{g}$ is the geometric standard deviation.

stages of plume transport during the first few hours since a fire [Trentmann et al., 2002]. To our knowledge, this is the first time that a combination of in situ, and also airborne/ ground-based lidar measurements, have been used to estimate the time evolution of AOPs over several days, and their subsequent impact on photolysis rates and photochemistry during long-range transport.

\subsection{Calculation of Aerosol Optical Properties}

[21] During the campaign, the DLR Falcon aircraft was equipped with extensive in situ aerosol instrumentation. The data has been used to derive particle size distributions, particle number densities, and particle absorption coefficients. More information on the aerosol measurements is given by Petzold et al. [2007]. Aerosol measurements in the $\mathrm{BB}$ plume on 23 July were used to derive the refractive index, and size distribution of the $\mathrm{BB}$ aerosols following the procedure described by Fiebig et al. [2002]. This information was then used as input in a Mie code to derive BB AOPs [Mishchenko et al., 1999].

[22] Firstly, a composite size distribution in the plume was derived from the measurements, and a three-modal logarithmic normal distribution was fitted to the particle size distribution [see Petzold et al., 2007, Figure 9]. Each of these three modes were parameterized by integral particle number concentration, $\mathrm{N}$, particle median radius, $\mathrm{r}_{m}$, and the geometric standard deviation, sigma $\left(\sigma_{g}\right)$, as given in Table 2.

[23] For the refractive index calculation, an internal mixture of ammonium sulfate and soot was used with a soot fraction of $3.8 \%$. As noted previously, a large fraction of the aerosol likely consisted of organic carbon, but here ammonium sulfate is used as a surrogate since it has a similar refractive index [Sloane, 1984]. The soot fraction of $3.8 \%$ was derived from the measurements [Petzold et al., 2007] so that the calculated absorption coefficient matched the measurements as closely as possible. The hypothesis of internal mixing was also confirmed by the measurements. Finally, the calculated refractive index using these hypotheses was $1.54+0.0168 \mathrm{i}$.

[24] With these assumptions about the aerosol size distributions, and the refractive index, the extinction efficiency $(\mathrm{Q})$, the single scattering albedo $\left(w_{0}\right)$, and the first 8 terms of the Legendre expansion of the scattering phase function $\left(w^{i}, \mathrm{i}=0,7\right)$ were calculated for 3 wavelengths characteristic of ultraviolet (UV) and visible wavelengths (300, 400 and $600 \mathrm{~nm}$ ) using the Mie code. These results were directly used in the Fast-J code to simulate BB aerosol optical properties and are summarized in Table 3 . In the selected $\mathrm{BB}$ plume, $w_{0}$, which represents the fraction of scattering versus light absorption by aerosols, is in the upper range of previous estimates derived from measurements in aged boreal and North American fire plumes (0.85 to 0.91 over wavelengths from 400 to $700 \mathrm{~nm}$ ) [Reid et al., 2005].

\subsection{Calculation of Aerosol Optical Depth}

[25] AOPs alone are not sufficient to describe the effect of a $\mathrm{BB}$ plume on photolysis rates. Information about aerosol concentrations, and their vertical distribution are also required. This information is given by the optical depth (OD) of the aerosol layer which corresponds to the integration of the extinction coefficient over a layer. During long-range transport of an aerosol layer, the OD changes with time as the layer becomes dispersed. Here, two ODs were derived from in situ measurements of the DC8 aerosol lidar on 18 July and from the DLR Falcon on 23 July [Petzold et al., 2007]. On 18 July an OD of 0.2 at $1024 \mathrm{~nm}$ and 0.3 to 0.4 at $550 \mathrm{~nm}$ was evaluated for the BB layer with an estimated vertical dimension of $7 \mathrm{~km}$ which corresponded to a strong increase in the backscatter signal from the DC8 lidar (see Figure 3). For 23 July, a layer thickness of $2 \mathrm{~km}$ was used to calculate the aerosol optical depth at $550 \mathrm{~nm}$ using an average aerosol absorption coefficient of $6.5 \times 10^{-6} \mathrm{~m}^{-1}$, and a single-scattering albedo of 0.9 at $550 \mathrm{~nm}$. The height of the layer was taken from vertical profile data collected by the Falcon spanning 3.5 to $5.5 \mathrm{~km}$. The aerosol absorption coefficient was determined from PSAP (Particle Soot Absorption Photometer) data assuming that the layer-averaged value of the absorption coefficient corresponds to $75 \%$ of the peak value inside this layer which was $9 \times 10^{-6} \mathrm{~m}^{-1}$ [Petzold et al., 2007]. These values yield an aerosol optical depth of 0.13 for the BB layer probed by the Falcon on 23 July.

[26] In addition, a dual wavelength depolarization aerosol lidar operated by the SIRTA Observatory in Palaiseau [Haeffelin et al., 2005], southwest of Paris at about the same location as the Falcon measurements, reported, approximately 1 hour before the Falcon sampling, a layer extending from 2.5 to $5.5 \mathrm{~km}$ with high aerosol loading. The lidar data was analyzed using a multitest algorithm applied to all the lidar channels. The layer consisted of a lower layer between 2.5 and $4.0 \mathrm{~km}$ characteristic of BB aerosols (1064/ $532-\mathrm{nm}$ color ratio of about 0.25 and $2 \%$ depolarization), and an upper layer between 4.0 and $5.5 \mathrm{~km}$ containing larger particles ( 0.5 color ratio). No measurements were available later on this day, but it is likely that this BB layer was part of the same BB layer observed by the Falcon. An optical depth of 0.1 to 0.15 was estimated for the entire layer on the basis of the lidar power attenuation between the

Table 3. Aerosol Optical Properties at Three Wavelengths (Calculated With a Refractive Index of $1.54+0.0168 \mathrm{i}$ at $550 \mathrm{~nm}$ )

\begin{tabular}{|c|c|c|c|c|c|c|c|c|c|c|}
\hline$\lambda, \mathrm{nm}$ & $Q$ & $w_{0}$ & $w^{0}$ & $w^{1}$ & $w^{2}$ & $w^{3}$ & $w^{4}$ & $w^{5}$ & $w^{6}$ & $w^{7}$ \\
\hline 300 & 2.6700 & 0.9160 & 1 & 2.143 & 2.528 & 2.236 & 1.688 & 1.127 & 0.686 & 0.369 \\
\hline 400 & 1.9490 & 0.9140 & 1 & 2.014 & 2.040 & 1.480 & 0.892 & 0.447 & 0.232 & 0.114 \\
\hline 600 & 0.8600 & 0.8950 & 1 & 1.689 & 1.330 & 0.671 & 0.331 & 0.162 & 0.097 & 0.063 \\
\hline
\end{tabular}




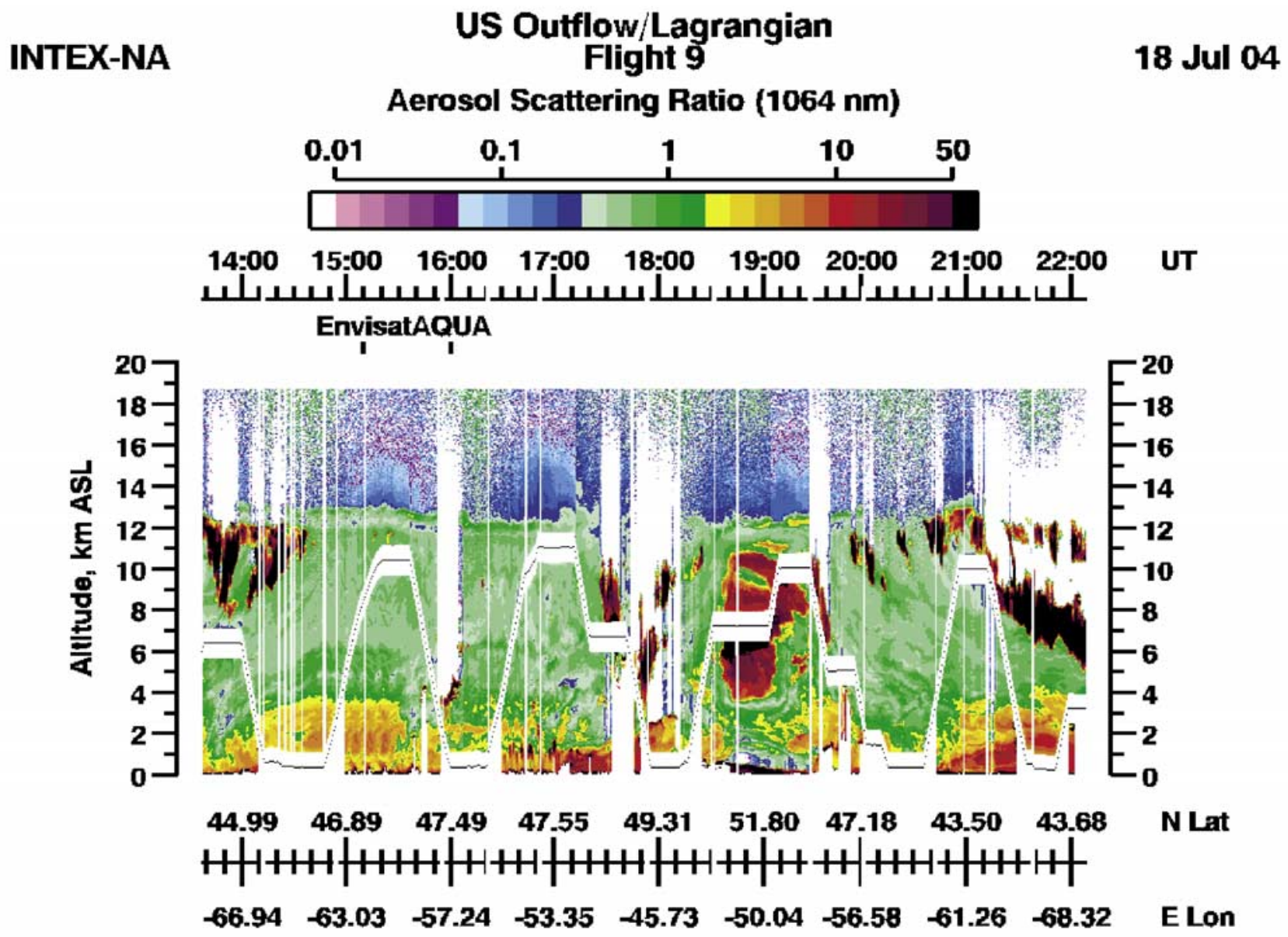

Figure 3. Aerosol scattering ratio as measured by the DC8 onboard lidar on 18 July 2004. A strong signal is seen at the same location as high CO in situ data (1830 and 1915 UT) including the Lagrangian match (1839-1902 UT).

observed lidar return above the aerosol layer, and the theoretical molecular lidar return in the absence of aerosols [Cadet et al., 2005]. This confirms that, even if the Falcon may not have sampled the entire vertical distribution of the BB plume, the Falcon profile was representative of the main vertical extent of this aerosol layer.

\subsection{Photolysis Scheme Evaluation}

[27] In order to evaluate the performance of the Fast-J code for this case, simulated and measured $\mathrm{jNO}_{2}$ values were compared by running the code along the DC8 flight track for 18 July (see Figure 2). This flight was chosen because a clear signal was seen in the measured data when the aircraft passed through the BB aerosol layer (as seen by the onboard aerosol lidar), and measured photolysis rates were reduced. In a run with no clouds or BB aerosols the model significantly overestimates the data between 1815 and 2100 UT. This time window corresponds to an increase in the measured upward $\mathrm{jNO}_{2}$ flux and high aerosol scattering ratios observed by DC8 backscatter lidar at low levels indicating the presence of low cloud. The agreement is partially improved by including a low cloud layer (see Figure 2, blue rectangle) with an OD of 5 extending from 0 to $0.5 \mathrm{~km}$ between 1815 and 2100 UT (solid line).
However, measured $\mathrm{jNO}_{2}$ is still overestimated in the $\mathrm{BB}$ plume (see coincident $\mathrm{CO}$ data). A further run was performed including a BB aerosol layer with an OD of 0.3 (see Figure 2, red rectangle) collocated with the high aerosol scattering ratio signal measured by the DC8 lidar between 4 and $11 \mathrm{~km}$ (Figure 3). AOPs were prescribed as discussed previously. The $30 \%$ reduction in $\mathrm{jNO}_{2}$ observed in the $\mathrm{BB}$ plume (dashed line) is now simulated well by the model suggesting that the AOPs used in the Fast-J code are reasonably realistic. Observed photolysis rates of other species like $\mathrm{O}_{3}$ or PAN are also reduced in the BB plume, and well simulated by the run including the effects of $\mathrm{BB}$ aerosols. The impact of these changes on $\mathrm{O}_{3}$ levels are discussed in the next section.

\section{Results}

[28] In this section, results are discussed from CiTTyCAT simulations initialized with data on 18 July and run for 5 days. Firstly, the impact of high aerosol loading on photolysis rates, and photochemistry in the plume are discussed. Then, the influence of both chemical processes, and dynamical processes related to mixing with other air masses during transport, are examined, and results com- 
pared to observations collected downwind during the Lagrangian matches.

\subsection{Aerosol Impact on Photolysis Rates}

[29] Concerning the inclusion of BB aerosols in Fast-J for this case, several assumptions, and simplifications had to be made. The aerosol layer was assumed uniform in aerosol concentration, and its thickness was varied from $7 \mathrm{~km}$ on 18 July to $3 \mathrm{~km}$ on 23 July with the OD decreasing linearly from 0.3 to 0.13 over 5 days. It was also assumed that the trajectory was situated in the middle of the BB plume. The DC8 lidar data (see Figure 3) confirms that the DC8 match is, indeed, in the middle of the $\mathrm{BB}$ plume, and the $\mathrm{CO}$ vertical profile measured by the Falcon on 23 July also shows that the Falcon match is approximately located in the middle of the plume.

[30] In this study, BB aerosols were considered as an internal mixture of black carbon, an absorbent component, and sulfate, which has scattering properties. In an absorbing aerosol layer, available light is reduced, and therefore photolysis rates decrease whereas they can be enhanced in a scattering aerosol layer. For a mixture, the relative influence of scattering versus absorption depends on the solar zenith angle, SZA. Scattering properties outweigh absorption properties at low SZA, but their influence decreases with SZA. This dependence of the scattering/ absorption with SZA is dominated by the shape of the aerosol phase function which can vary strongly depending on the refractive index, and the size distribution of the aerosols. SZA dependence was strong for the BB aerosols in this case, and at lower SZA the photolysis rates were even enhanced when aerosols were included. Consequently, measured photolysis rates should be analyzed carefully because changes due to the presence of $\mathrm{BB}$ aerosols will depend on SZA, and therefore on the time of day when the measurements were made. Another important aspect of the BB AOPs is their dependence on the size parameter, $2 \pi r / \lambda$ with $r$ being the mean aerosols radius and $\lambda$ the wavelength. For small particles, this leads to an inverse dependence of the single scattering albedo on wavelength in the UV. This means that for a single particle, smaller wavelengths will be absorbed less. However, a plume contains thousands of particles which interact with each other leading to more complex effects which depend, not only on the single scattering albedo, but also on SZA, the optical depth, and the aerosol phase function [Reuder and Schwander, 1999].

[31] The BB aerosol impact obtained by averaging over the 5 day simulation resulted in a reduction in all photolysis rates, and in particular, a reduction of $-21 \%$ for $\mathrm{jNO}_{2}$ compared to $-22 \%$ for $\mathrm{jO}_{3}$. This can be compared with results from Duncan et al. [2003] for Indonesian fires where monthly averaged reductions in $\mathrm{jNO}_{2}$ and $\mathrm{jO}_{3}$ in the $\mathrm{FT}$ over source regions were around -10 to $-20 \%$ using a mean AOD of 0.3 . Simulated photolysis rate reductions in a Mexican fire transported into Arizona were larger $(-20$ to $-60 \%$ ), but this study used a lower value of the single scattering albedo (0.82) than used here [Kotamarthi et al., 2006]. Also, in contrast to our simulation, $\mathrm{jNO}_{2}$ was reduced more than $\mathrm{jO}_{3}$ because different size distributions and refractive indexes were used. This shows that results are very sensitive to the AOPs parameters used for particular fire events.
[32] In this case, the reduction in photolysis rates leads to a slowing down of the photochemistry with a reduction of $-18 \%$ in $\mathrm{O}_{3}$ production and $-24 \%$ in $\mathrm{O}_{3}$ destruction. $\mathrm{O}_{3}$ production is reduced mainly because lower $\mathrm{jNO}_{2}$ leads to reductions in $\mathrm{NO}$ plus $\mathrm{HO}_{2} \cdot \mathrm{O}_{3}$ destruction is mainly due to the reaction of $\mathrm{O}^{1} \mathrm{D}$ with water vapor, and this term is reduced the most when aerosols are included because of the reduction in $\mathrm{jO}_{3}$. However, this term, and also the second most important $\mathrm{O}_{3}$ loss term (reaction with $\mathrm{HO}_{2}$ ) are also reduced because of lower $\mathrm{O}_{3}$ levels resulting from less $\mathrm{O}_{3}$ production. The overall effect of including these effects on net $\mathrm{O}_{3}$ production depends on the balance between production and destruction. Changes in photolysis rates due to the inclusion of $\mathrm{BB}$ aerosols will reduce net $\mathrm{O}_{3}$ production in a plume mainly producing $\mathrm{O}_{3}$, and increase net $\mathrm{O}_{3}$ production in a plume mainly destroying $\mathrm{O}_{3}$. It will be seen in section 7 that after 8 days of simulation, the plume enters a net $\mathrm{O}_{3}$ destruction regime. From this moment, the reduction in photolysis rates leads to an increase in $\mathrm{O}_{3}$ production.

\subsection{Chemistry-Only Simulation Including Aerosol Photolysis Rate Effects}

[33] Simulated concentrations over 5 days of $\mathrm{CO}, \mathrm{O}_{3}$, $\mathrm{NO}_{y}, \mathrm{NO}, \mathrm{PAN}$ and water vapor are shown in Figure 4 , and compared to the range of measured values along the matching Lagrangian segments on 20 July (BAe146), and 23 July (DLR Falcon). In order to better characterize the variation of the chemical composition in the plume, 3 chemical initializations were used. One using mean observed DC8 values (black lines), and two others using mean \pm standard deviation (std) values (red and blue dashed lines). It should be noted that the red (blue) simulation corresponds to initialization with the mean + std $(-$ std) for species like CO, VOC, PAN, but the mean - std $(+$ std) for $\mathrm{O}_{3}$, since $\mathrm{O}_{3}$ is anticorrelated with precursors such as $\mathrm{CO}$.

[34] The first important discrepancy in the results is found between the simulated and observed concentrations of $\mathrm{CO}$. The small CO decrease observed during the first 2 days is well reproduced by the model but after 5 days $\mathrm{CO}$ is overestimated by more than 150 ppbv. $\mathrm{NO}_{y}$ is also overestimated by about 1000 pptv after 5 days. As will be seen in the next section, these overestimations are likely to be due to dilution of the plume during transport.

[35] Despite the large discrepancies in $\mathrm{CO}$ and $\mathrm{NO}_{y}$, it is still interesting to examine this chemistry-only simulation in order to understand the photochemical processes in such BB plumes during long-range transport. The large $\mathrm{O}_{3}$ increase, of about 17 ppbv, observed over 5 days between the DC8 and the Falcon matches, is reproduced, and even overestimated by the chemistry-only simulation giving a mean $\mathrm{O}_{3}$ increase of $22 \mathrm{ppbv}$ in 5 days just due to photochemistry.

[36] Diagnosis of model results for these chemistry-only simulations shows that the large increase in $\mathrm{O}_{3}$ is mainly due to the high PAN loading in the plume. PAN is stable at the low temperatures encountered during the first 2 days of the simulation, but rapidly decomposes at high temperatures encountered once the plume subsided leading to release of $\mathrm{NO}_{2}$, and resulting in increased $\mathrm{O}_{3}$ production. Unfortunately, downwind PAN measurements are not available but modeled NO values fall within the range of the observations on both 20 and 23 July. Note that in these runs, $\mathrm{NO}_{y}$ levels in the plume are maintained because part of the $\mathrm{NO}_{2}$ 

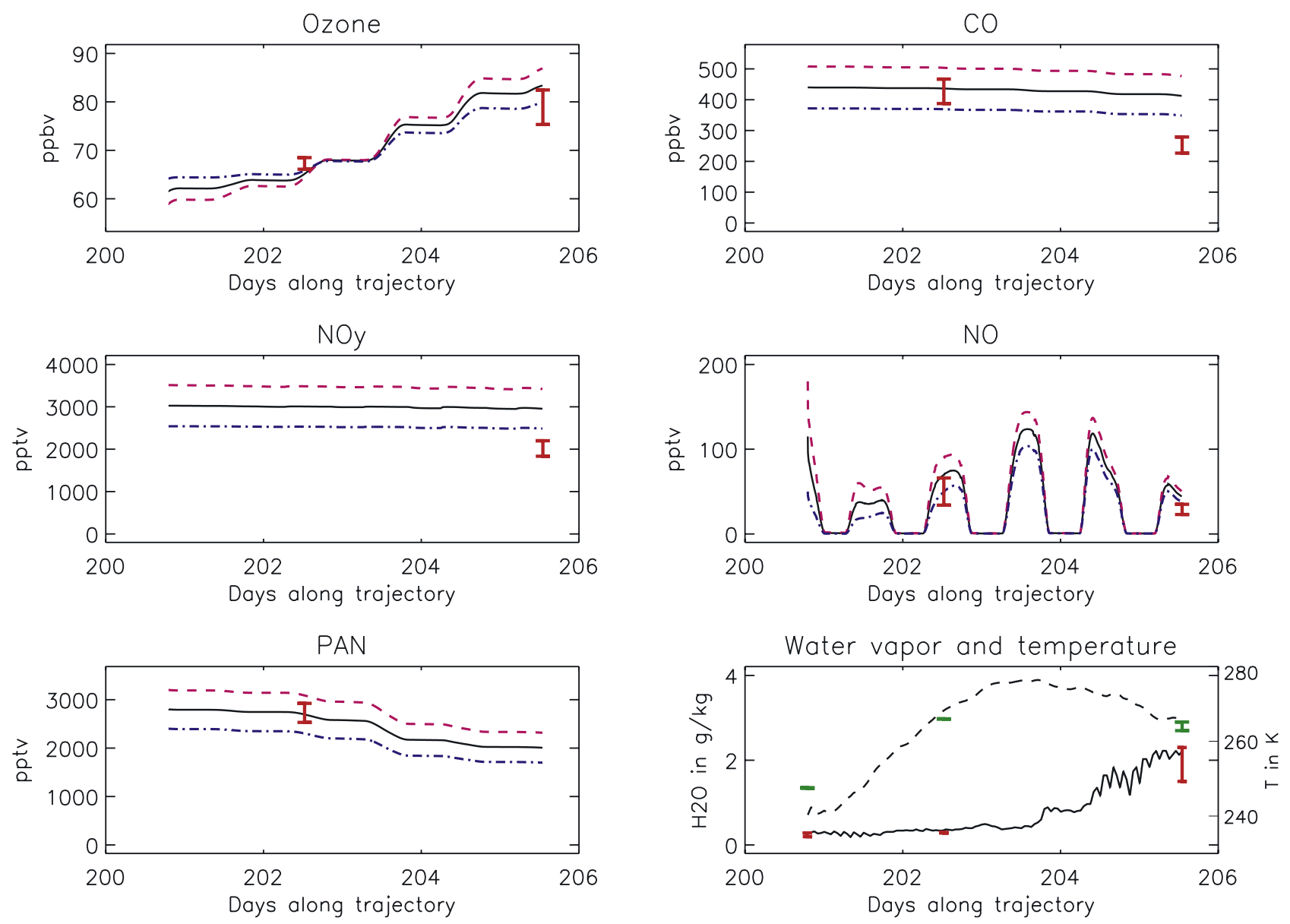

Figure 4. Time evolution of traces gases mixing ratios, water vapor (specific humidity in $\mathrm{g} / \mathrm{kg}$ ) and temperature (in K) from CiTTyCAT simulations. The simulations were initialized with mean plus/minus standard deviation measurements in the DC8 plume and represented respectively as solid black lines and dotted color lines (blue for mean - std, pink for mean + std). Vertical red bars correspond to measurements made in the plume by the BAe-146 aircraft (20 July, 202 Julian days) and the DLR Falcon aircraft (23 July, 205 Julian days). For the water vapor and temperature panel, the solid line represents the simulated water vapor (specific humidity) and the dotted line the simulated temperature (from ECMWF). Red and green vertical bars represent the water vapor and temperature measurements, respectively.

released from PAN decomposition is transformed into $\mathrm{HNO}_{3}$ which makes up about $30 \%$ of $\mathrm{NO}_{y}$ on 23 July.

[37] In order to illustrate the effect of temperature on PAN decomposition, several stationary steady state runs at a fixed position, corresponding to the location where the DC8 sampled the plume, were performed. Mean DC8 measurements, together with scaled PAN, in the plume were used for the chemical initialization, and only the temperature varied between each run. Values of PAN and $\mathrm{O}_{3}$ after 1 day of simulation are shown in Figure 5. At temperatures lower than $260 \mathrm{~K}$ no changes in PAN are seen. PAN thermal decomposition begins at temperatures higher than $260 \mathrm{~K}$, and is nonlinear with temperature especially beyond $270 \mathrm{~K}$. At $290 \mathrm{~K}, 90 \%$ of the initial PAN has decomposed after 1 day. Therefore increasing temperature higher than $290 \mathrm{~K}$ will not have a strong effect as most of the PAN has already decomposed thus limiting the potential for further $\mathrm{O}_{3}$ production. It is interesting to note that the value of $90 \%$ PAN decomposition after 1 day at $290 \mathrm{~K}$ is not dependent on the initial PAN value. This also explains why,

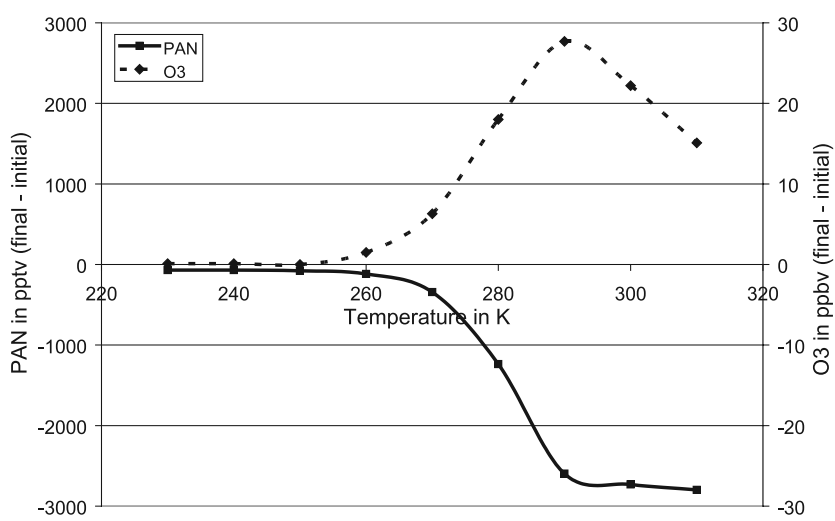

Figure 5. Change in PAN mixing ratio (in pptv) and $\mathrm{O}_{3}$ mixing ratio (in ppbv) after 1 day of stationary simulation, initialized with DC8 measurements and run at different temperatures. 
in the simulation, even if the simulated temperature increases by $25 \mathrm{~K}$ (from 240 to $265 \mathrm{~K}$ ) between the DC8 and the BAe146 matches, only a small fraction of PAN is decomposed.

[38] In model runs with and without PAN, it was found that PAN decomposition accounts for $80 \%$ of the total $\mathrm{O}_{3}$ increase between DC8 and Falcon matches. In the run without PAN, conversion of the initial $\mathrm{NO}$ loading into $\mathrm{O}_{3}$ through $\mathrm{NO}_{2}$ photolysis is only sufficient to maintain net $\mathrm{O}_{3}$ production during the first 2 days resulting in net $\mathrm{O}_{3}$ destruction over 5 days. Since PAN has a central role in governing $\mathrm{O}_{3}$ production, it is important to consider uncertainties in the PAN decomposition rate which can vary by $\pm 100 \%$ at $280 \mathrm{~K}$ according to the latest International Union of Pure and Applied Chemistry (IUPAC) recommendations (http:// www.iupac-kinetic.ch.cam.ac.uk). Increasing this rate by a factor of 2 leads to faster PAN decomposition, lower PAN (by 500 pptv), and higher $\mathrm{O}_{3}$ (by 6 ppbv) concentrations on 23 July. However, this represents a 10 ppbv overestimation of the Falcon data in the chemistry-only runs.

[39] It is clear that physical variables such as temperature and water vapor are also important in governing the production and destruction of $\mathrm{O}_{3}$ during long-range transport of such plumes. Comparison of observed values in the plume, and values interpolated from ECMWF analyzes are shown in Figure 4. Analyzed and measured water vapor, as given by specific humidity agree well. Nevertheless, it is interesting to see how $\mathrm{O}_{3}$ levels respond to changes in water vapor. Water vapor in the plume is low during the 5 first days so that halving the water vapor content in the model has a very small impact on net $\mathrm{O}_{3}$ production (less than $1 \mathrm{ppbv})$. On the contrary doubling the water vapor content along the trajectory increases $\mathrm{O}_{3}$ destruction, and leads to a decrease of $18 \%$ in net $\mathrm{O}_{3}$ production.

[40] Measured and simulated temperatures agree reasonably well except at the beginning of the simulation where temperatures are underestimated by more than $7 \mathrm{~K}$ on 18 July, in part because the trajectory used passes slightly above the DC8 match. However, increasing the initial temperature to match the measured one does not change $\mathrm{O}_{3}$ production very much as both temperatures are too low for PAN decomposition. Measured temperatures during the BAe-146 and the Falcon matches are similar but ECMWF analyses show that between these two matches, the temperature reached $278 \mathrm{~K}$ (at the southern most point along trajectory), resulting in the large $\mathrm{O}_{3}$ production. A sensitivity test with a constant temperature between these two matches gives a decrease of $41 \%$ in net $\mathrm{O}_{3}$ production, and therefore much lower $\mathrm{O}_{3}$ after 5 days ( 9 ppbv less).

[41] These sensitivity studies emphasize the importance of specific humidity and temperature for $\mathrm{O}_{3}$ chemistry. Therefore it is important that meteorological parameters used by models agree as closely as possible with observations. The evolution of meteorological parameters along the plume transport pathways is also crucial for estimating $\mathrm{O}_{3}$ levels and cannot be inferred from measured values alone. It will also be shown (in section 7) that water vapor and temperature play a key role in determining $\mathrm{O}_{3}$ levels in plumes transported into the lower troposphere where high water vapor can lead to strong $\mathrm{O}_{3}$ destruction balanced by $\mathrm{O}_{3}$ production through PAN decomposition.
[42] Overall, while chemical changes alone could explain observed $\mathrm{O}_{3}$ changes during plume transport, they cannot explain the observed changes in $\mathrm{CO}$ and $\mathrm{NO}_{y}$.

\subsection{Simulation of Mixing/Dilution of the BB Plume}

[43] In the previous section, model runs with no mixing were discussed, and the plume was assumed to be isolated from the background and not diluted. In the real atmosphere, a plume is subject to stirring by large-scale winds followed by mixing. This mixing process entrains surrounding air masses, and thus changes concentrations in the plume [Stohl, 2001]. The scheme for mixing in CiTTyCAT is a simple linear relaxation scheme [Evans et al., 2000] resulting in an exponential decay of plume concentrations toward background concentrations. The rate of mixing is defined by the e-folding timescale, $K_{m i x}$ in days ${ }^{-1}$ which can also be written in terms of a mixing timescale, $\tau$ in day $\left(\tau=\frac{1}{K_{m i x}}\right)$. This scheme requires the estimation of so-called background concentrations as well as the mixing timescale. In this study, instead of trying to estimate average background concentrations, concentrations were defined using in situ measurements in air masses adjacent to the BB plume. The mixing timescale was chosen in order to obtain the best agreement between measured and modeled $\mathrm{CO}$ which is a good tracer for mixing since it is relatively long lived on the timescales considered here, and not, generally, strongly affected by chemistry. A strong decrease in $\mathrm{CO}$ is thus characteristic of mixing/dilution of the plume.

[44] Analysis of observed $\mathrm{CO}$ in the plume showed a small CO decrease between the DC8 and the BAe146 matches, and a much stronger one between the BAe146 and the Falcon when the plume reached western Europe (decrease of $40 \%$ of BAe146 CO). Trajectory analysis showed that just south of the BAe-146 match, trajectories reached a stagnation point, and switched from descent in quiescent clear air to being near a warm conveyor belt moving up from the southwest that was likely to be more turbulent. This resulted in a change in direction in the transport pathway (see Figure 1). It is thus realistic to simulate two mixing regimes representative of these different situations: a slow mixing timescale (20 days) during the 2 first days of simulation followed by a faster one ( 5 days), leading to an integrated mixing timescale of 6.25 days.

[45] The values of these mixing timescales, chosen to match the $\mathrm{CO}$ measurements, are dependent on whether the same parts of the plume were sampled since, in reality, strong gradients exist at plume extremities. Lagrangian matches are not perfect and it is possible, for example, that the Falcon may have missed the center of the plume sampled by the DC8 explaining the large difference in measured CO. However, other parts of the same large plume were sampled over Europe by different platforms and the measured $\mathrm{CO}$ was in the same range as the Falcon data or lower (see section 7). It is also worth noting that, if the same mixing rates are applied to aerosols in the plume (i.e., mixing the DC8 OD with a zero background), this leads to a decrease from 0.3 to 0.128 after 5 days, which is consistent with the estimated OD on 23 July from in situ measurements and lidar data. This supports the choice of the mixing rates used in this study.

[46] Concerning background values, Methven et al. [2006] showed that this BB plume was situated within a 
Table 4. Mixing Ratios of $\mathrm{CO}, \mathrm{O}_{3}, \mathrm{NO}_{y}$, and NO Measured in Air Masses in Close Proximity to the BB Plume and Used as Background Concentrations for the Mixing Simulation (See Text for Details)

\begin{tabular}{lllll}
\hline & $\mathrm{CO}$ & $\mathrm{O}_{3}$ & $\mathrm{NO}_{v}$ & $\mathrm{NO}$ \\
\hline $\mathrm{UT}$ & 94 & 105 & 900 & 120 \\
FT & 105 & 70 & 550 & 8 \\
\hline
\end{tabular}

dry intrusion that had descended from close to the tropopause over North America. DC8 measurements of $\mathrm{CO}, \mathrm{O}_{3}$ and data from the $\mathrm{O}_{3}$ and backscatter lidars also clearly show that the BB plume was in close proximity to air with low $\mathrm{CO}$ and high $\mathrm{O}_{3}$ concentrations, characteristic of the UT. It is therefore reasonable to imagine that the BB plume and UT air masses have mixed. Therefore, initially, the DC8 measurements in the UT air mass were used to constrain background concentrations (see Table 4) together with a mixing timescale of 20 days during the first 2 days, and 5 days during the last 3 days. In results from this run (not shown) $\mathrm{O}_{3}$ was overestimated by more than 7 ppbv compared to the Falcon measurements.
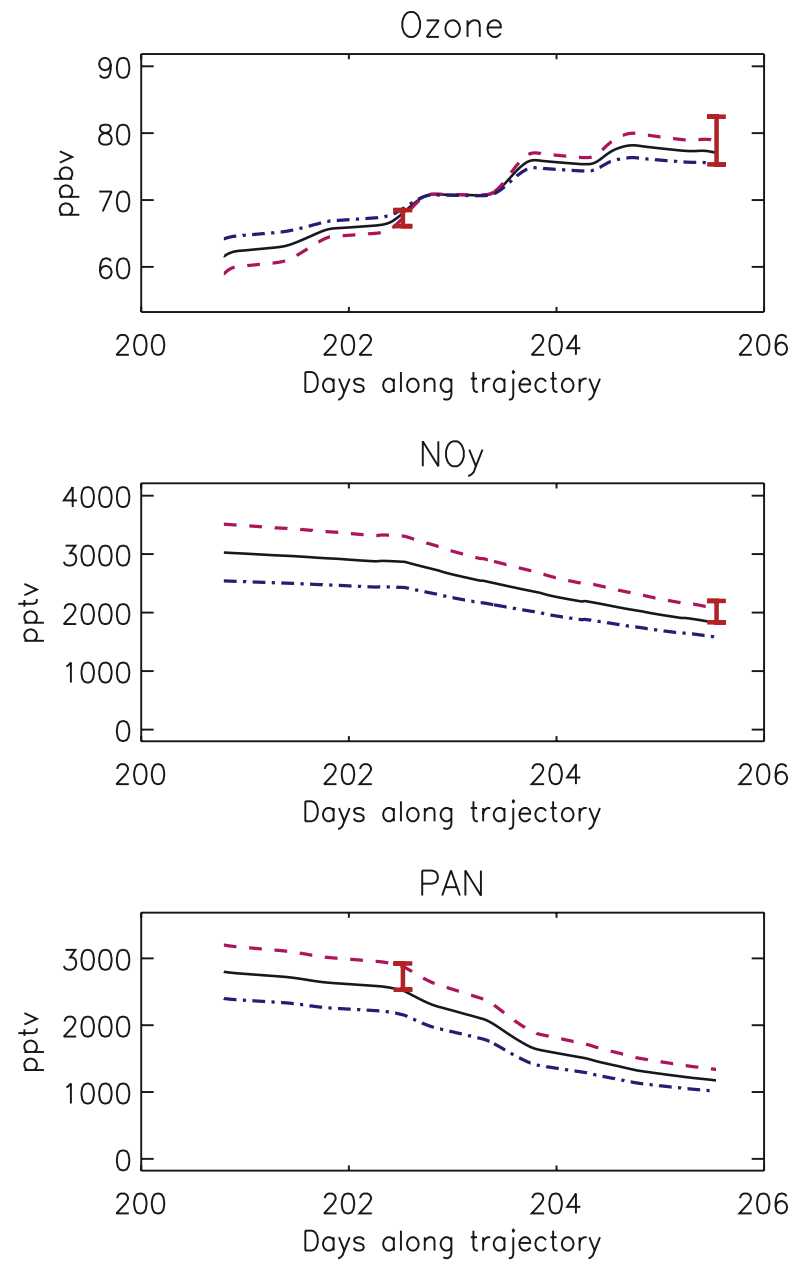

[47] Examination of ECMWF water vapor suggests that there was mixing of wetter air into the plume where the transport pathway changed direction (see water vapor in Figure 4). This corresponds to when the BB plume lost contact with drier air above and to the north, and came into contact with more moist air from the south associated with a warm conveyor belt. Evidence for this split between the BB plume and UT air masses is also seen in satellite water vapor images for 20 and 21 July (O. R. Cooper, personal communication, 2006; see http://www.esrl.noaa.gov/csd/ metproducts/icartt2004/). Therefore a second run was performed where both the mixing timescale and background concentrations were changed after 2 days in an attempt to represent changes in the composition of air masses mixing into the BB plume. In fact, air masses sampled by the Falcon next to the plume on 23 July were typical of free tropospheric (FT) air masses, and had higher water vapor content and lower $\mathrm{O}_{3}$ than the UT air mass. These measurements were used to constrain background concentrations during the last 3 days of the simulation (see Table 4).

[48] Results using UT/FT background concentrations are shown in Figure 6. Simulated $\mathrm{O}_{3}$ and $\mathrm{CO}$ agree very well
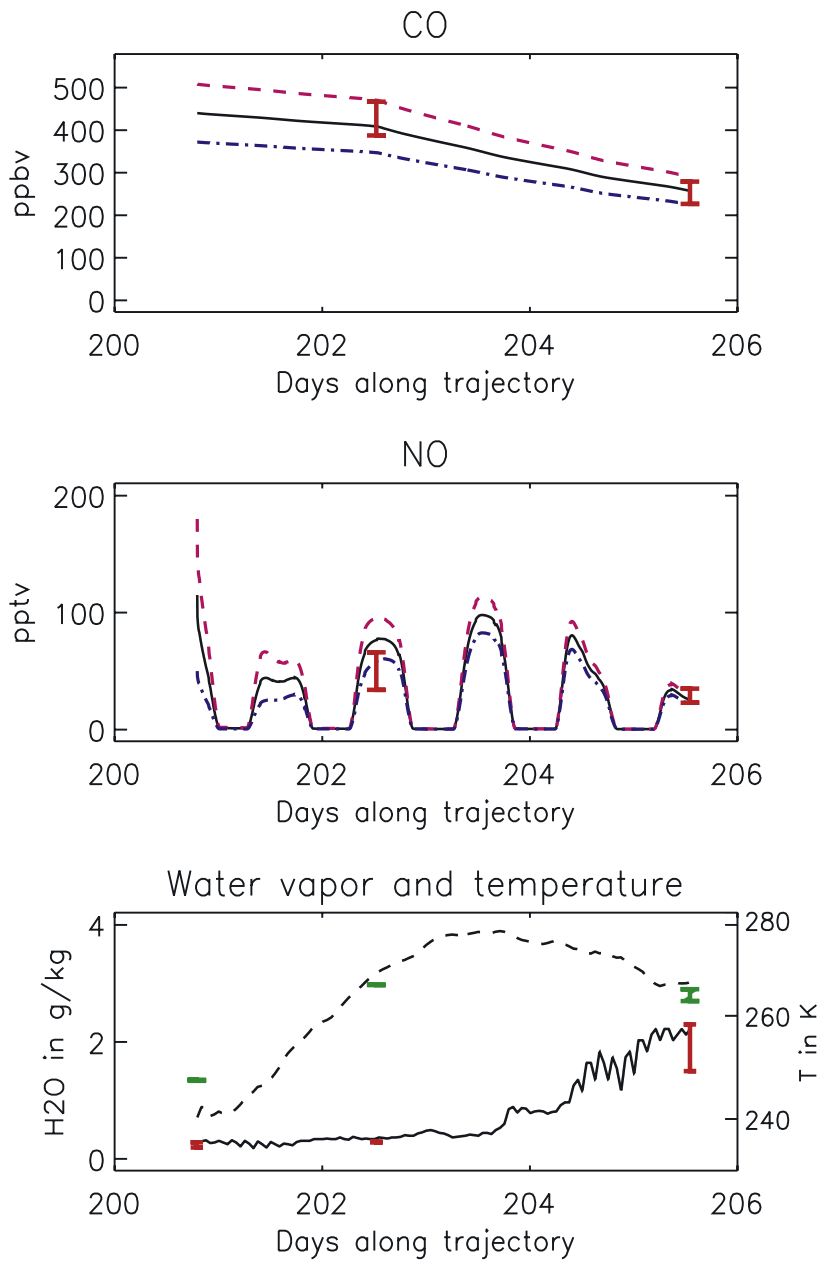

Figure 6. Time evolution of traces gas mixing ratio, water vapor $(\mathrm{g} / \mathrm{kg})$ and temperature $(\mathrm{K})$ from CiTTyCAT simulations including mixing with UT air masses and with a mixing timescale of 20 days during the first 2 days and mixing with FT air masses and a mixing timescale of 5 days during the last 3 days. Caption is the same as Figure 4. Background concentrations are given in Table 4. 


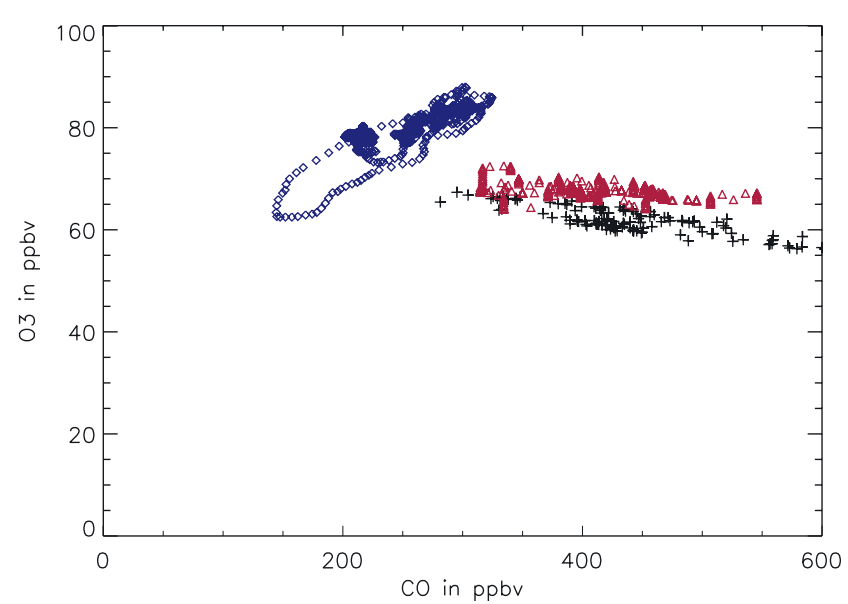

Figure 7. Observed $\mathrm{O}_{3}$ mixing ratio versus observed $\mathrm{CO}$ mixing ratio from the DC8 match (black crosses), the BAe146 match (red triangles) and the Falcon match (blue diamonds).

with Falcon measurements giving some confidence in the hypothesis that the BB plume mixed first with a UT air mass before mixing with a FT air mass. As both UT and FT mixed air are poor in PAN and $\mathrm{HNO}_{3}, \mathrm{NO}_{y}$ in the plume is reduced by about 1000 pptv leading to good agreement with the Falcon measurements. The final breakdown in modeled $\mathrm{NO}_{y}$ on 23 July is $55 \%$ PAN, $3 \% \mathrm{NO}_{x}$ and $42 \% \mathrm{HNO}_{3}$. Simulated NO values are still in the range of the measurements because NO is a reactive specie, governed by photochemistry in the plume (PAN decomposition), and so not strongly influenced by mixing. It is interesting to note that mixing not only changes concentrations in the plume by introducing background air, but can also change the photochemistry in the plume. In this case, the main effect is dilution of PAN in the plume leading to a reduction of net $\mathrm{O}_{3}$ production in the plume by $10 \%$.

[49] Overall, these results show that inclusion of mixing processes, albeit in a simple manner, produce results in better agreement with the full range of measurements.

\section{6. $\mathrm{O}_{3} / \mathrm{CO}$ Correlations}

[50] In the previous section, it was shown that a combination of photochemistry and mixing with UT/FT air masses can explain the evolution of the BB plume since the results agree reasonably well with the observations for several trace gases. However, it is very difficult to know the real composition of mixed air masses, and thus to evaluate the relative contributions of photochemistry and mixing. For example, mixing of the plume with a UT air mass could lead to a large $\mathrm{O}_{3}$ increase in the plume even if the plume does not undergo any photochemical production. It is therefore possible that both photochemistry and mixing simulations could be incorrect, but that the final results could match the observations because the effects of the different processes compensate each other. However, the proposed scenario can be tested more rigorously by examining the evolution of trace gas correlations, and more specifically, the slope of such correlations. Here, we focus on $\mathrm{O}_{3} / \mathrm{CO}$ correlations since $\mathrm{O}_{3}$ can change rapidly over several days because of photochemical processes, and $\mathrm{CO}$ is a good tracer of mixing over this time period. Indeed, if mixing in the plume is uniform, then $\mathrm{O}_{3} / \mathrm{CO}$ correlations are not changed by mixing processes and, in the absence of loss processes, any change in the slope can be attributed to photochemical processes alone. This assumes that all parts of the plume are mixed with the same background, and with the same mixing timescale at any point in time as was assumed in this study. Considering that the plume evolution is followed during only 5 days, and that the segment matches correspond to inside the plume and not the edges, this hypothesis of uniform mixing seems reasonable. Mixing processes could also have an indirect effect on $\mathrm{O}_{3} / \mathrm{CO}$ slopes $\left(\delta \mathrm{O}_{3} / \delta \mathrm{CO}\right)$ by diluting $\mathrm{O}_{3}$ precursors, thereby modifying photochemical processes in the plume.

[51] The case studied here is particularly interesting to look at in terms of $\mathrm{O}_{3} / \mathrm{CO}$ correlations since a 4 day old $\mathrm{BB}$ plume was measured by the $\mathrm{DC} 8$ with a negative $\delta \mathrm{O}_{3} /$ $\delta \mathrm{CO}$ value, an unusual feature in an ageing $\mathrm{BB}$ plume (see Figure 7). Negative values of $\delta \mathrm{O}_{3} / \delta \mathrm{CO}$ have been measured in young BB plumes because of titration [Stith et al., 1981; Hobbs et al., 2003] but most BB plumes observed during previous campaigns showed rapid $\mathrm{O}_{3}$ production, and positive $\delta \mathrm{O}_{3} / \delta \mathrm{CO}$ values after just a few hours [Goode et al., 2000; Andreae et al., 1988]. $\delta \mathrm{O}_{3} / \delta \mathrm{CO}$ measured by the BAe146 in the BB plume was still negative, but with a less steep slope than the DC8 (i.e., 6 days after emission). Aged $\mathrm{BB}$ plumes with negative correlations were also observed at the PICO-NARE station on the Azores during the ICARTT campaign [Val Martín et al., 2006]. The reason for these negative correlations in aged BB plumes is not clear. It does not necessarily mean that the plume has not undergone any photochemical $\mathrm{O}_{3}$ production but that the $\mathrm{O}_{3}$ production was not strong enough to change the initial negative slope to positive. High aerosol loadings over the source regions [Stohl et al., 2006; Duck et al., 2007] might have strongly dampened initial $\mathrm{O}_{3}$ production in these plumes or else other processes such as $\mathrm{O}_{3}$ loss by reaction with the organic component present in aerosols or nighttime chemistry including the heterogeneous hydrolysis of $\mathrm{N}_{2} \mathrm{O}_{5}$ [ Val Martín et al., 2006] might have played a role.

[52] In contrast, $\delta \mathrm{O}_{3} / \delta \mathrm{CO}$ measured by the Falcon was positive (see Table 5) with a value of 0.078 . This change from negative to positive slope after 5 days indicates that the plume was strongly chemically active as already suggested by the model results discussed previously. The slope value measured by the Falcon is in the lower range of values

Table 5. Values of the Observed and Simulated $\mathrm{O}_{3} / \mathrm{CO}$ Slopes $\left(\delta \mathrm{O}_{3} / \delta \mathrm{CO}\right)$ Under Several Conditions: With and Without Mixing, With and Without Clouds and With Increased PAN Decomposition Rate

\begin{tabular}{|c|c|c|c|c|c|c|c|}
\hline & Measured & Without Mixing/Clouds & With Mixing & With Cloud $(\mathrm{OD}=5)$ & Cloud OD $=10$ & Cloud OD $=20$ & PAN Rate $\times 2$ \\
\hline Slope/BAe146 & -0.00875 & -0.0151 & -0.008 & -0 . & -0.0125 & -0.0125 & -0.013 \\
\hline Slope/Falcon & 0.078 & 0.052 & 0.051 & 0.0542 & 0.0584 & 0.063 & 0.065 \\
\hline
\end{tabular}


a)

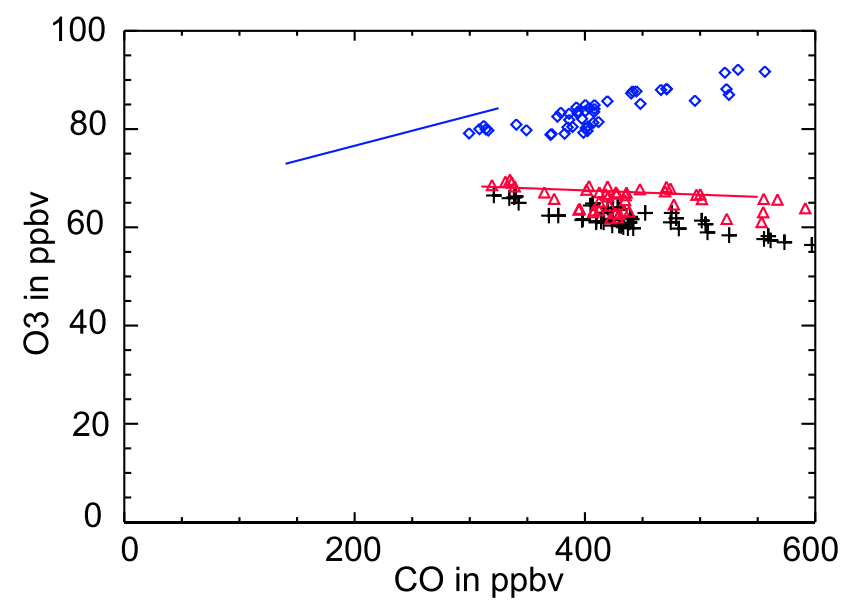

b)

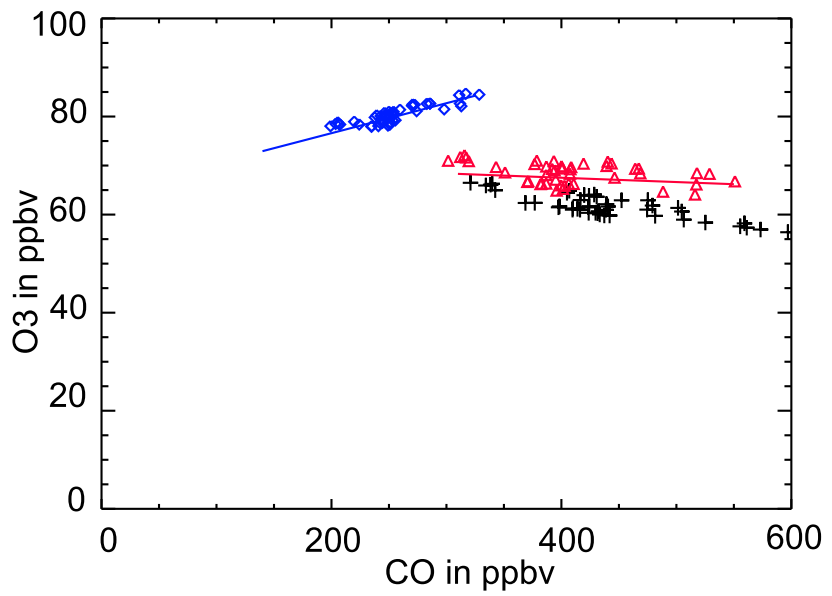

Figure 8. Measured $\mathrm{O}_{3}$ mixing ratio versus $\mathrm{CO}$ mixing ratio from the DC8 match (black crosses) used as initialization for the CiTTyCAT model and simulated $\mathrm{O}_{3}$ versus simulated $\mathrm{CO}$ after 2 days of simulation (red triangles) and after 5 days (blue diamonds). The lines represent fits to the measured correlations in the BAe-1 46 and Falcon matches. (a) Simulation without mixing and (b) simulation with mixing. See text for details.

reported for previous campaigns which range enormously from 0.045 to 0.88 [Andreae et al., 1988, 1994; Goode et al., 2000]. It is also lower than values reported by $\mathrm{Val}$ Martín et al. [2006] for BB plumes with positive correlations observed during the ICARTT campaign at the PICONARE station ranging from 0.14 to 0.89 . However, direct comparison of $\delta \mathrm{O}_{3} / \delta \mathrm{CO}$ is difficult because, in our study, the slope calculation is made in the Lagrangian sampling of the plume which does not include, for example, the edges of the plume, and represents only $\mathrm{CO}$ values larger than 150 ppbv (for the Falcon match). Using PICO-NARE measurements, Pfister et al. [2006] showed that if CO thresholds used to calculate $\delta \mathrm{O}_{3} / \delta \mathrm{CO}$ slopes in a plume are increased from 100 to $120 \mathrm{ppbv}$, then the slope value is almost divided by a factor 2 (from 0.44 to 0.26 ). This shows that $\delta \mathrm{O}_{3} / \delta \mathrm{CO}$ values are very sensitive to the range of values selected in the calculation.

[53] Therefore, in order to test the scenario put forward in the previous section, and in particular, the photochemistry in the model, multiple model simulations were conducted, initialized with DC8 measurements averaged every $30 \mathrm{~s}$ during the match segment. Modeled and measured $\mathrm{O}_{3} / \mathrm{CO}$ correlations and slopes were then compared downwind. With this method, each run represents a different part of the plume (black crosses in Figure 8) observed by the DC8, and thus the gradient across the plume. Simulation and comparison of $\delta \mathrm{O}_{3} / \delta \mathrm{CO}$ are relatively common with global models but, to our knowledge, this is the first time that such simulations have been performed with a photochemical trajectory model. Results from the multiple simulations after 2 (red triangles) and 5 (blue diamonds) days are shown for chemistry-only runs (Figure $8 \mathrm{a}$ ), and chemistry plus mixing (UT/FT) runs (Figure $8 b$ ). Observed $\mathrm{O}_{3} / \mathrm{CO}$ correlations are represented by linear fits to the data (solid lines). Measured and simulated slopes on the 20 and 23 July are also summarized in Table 5. Overall, the model simulations reproduce very well the change of $\delta \mathrm{O}_{3} / \delta \mathrm{CO}$ from negative for the DC8 and the BAe146 samplings to positive for the Falcon match. Values of the $\mathrm{O}_{3} / \mathrm{CO}$ slope are relatively well simulated but slightly underestimated. The results show that the main effect of mixing is to translate simulated $\mathrm{O}_{3} / \mathrm{CO}$ correlation lines toward background $\mathrm{CO}$ and $\mathrm{O}_{3}$ levels leading to better agreement with the range of measured concentrations. Only small changes are found between $\mathrm{O}_{3} /$ $\mathrm{CO}$ slopes for simulations with (slope of 5.1\%) and without (slope of 5.2\%) mixing. The slope is slightly decreased in the mixing run because of dilution of $\mathrm{O}_{3}$ precursors which decreases $\mathrm{O}_{3}$ production. In the following discussion all calculated slopes are from the chemistry plus mixing simulations.

[54] There are two explanations for the small discrepancy between measured and simulated $\delta \mathrm{O}_{3} / \delta \mathrm{CO}$ : the 3 matches are not perfect, and the limits of the matching plume are slightly different, or the model slightly underestimates the production of $\mathrm{O}_{3}$ per quantity of $\mathrm{CO}$, even if it reproduces the main features of the photochemical evolution of the plume. Concerning the possibility that different parts of the plume were sampled, it can be seen in Figure $8 \mathrm{~b}$ that the measured $\mathrm{CO}$ values during the Falcon match are more dispersed than those simulated by the model. This may suggest that the limits of the Falcon match are too large. For example, reducing the Falcon match window by 2 minutes leads to a reduction in the measured slope from $7.8 \%$ to $6.1 \%$, which is closer to the simulated value.

[55] Concerning the possible underestimation in modeled photochemical $\mathrm{O}_{3}$ production, two hypotheses have been examined: an increase in photolysis rates due to the presence of clouds, and an increase in the PAN decomposition rate (see section 5.2). Satellite images show that low clouds were present over Europe from 22 to 23 July, and Falcon $\mathrm{jNO}_{2}$ data collected on these 2 days often showed a strong variability with some very high values, typical of broken cloud fields. To see if an increase in the j-values due to the presence of low clouds could increase $\delta \mathrm{O}_{3} / \delta \mathrm{CO}$, sensitivity 
tests using different cloud ODs on 22 and 23 July were performed. $\delta \mathrm{O}_{3} / \delta \mathrm{CO}$ after 5 days of simulation were compared (see Table 5 for details). $\delta \mathrm{O}_{3} / \delta \mathrm{CO}$ increases slightly when increasing cloud OD, up to $6.3 \%$ with a cloud OD of 20. An increase by a factor two in the PAN decomposition rate leads to a final slope of $6.5 \%$. In both cases, simulated $\delta \mathrm{O}_{3} / \delta \mathrm{CO}$ are closer to the measured one, but mean simulated $\mathrm{O}_{3}$ levels in the plume are now overestimated by about 3 to 6 ppbv. Only a change in the mixing scenario could lead to better agreement with the mean plume value but this would require mixing with air masses with much lower $\mathrm{O}_{3}$ and no evidence for such air masses was found in the measurements made near the plume. In the case of doubling the PAN decomposition rate, $\mathrm{NO}_{y}$ values in the plume are also slightly underestimated. It is finally difficult to conclude on the reason for the small difference between simulated and observed slopes. It is likely to be due to the combined effects of non perfect match windows and a small underestimation in photochemical production, possibly due to either increased photolysis rates over clouds, or an underestimation in the PAN thermal decomposition rate.

[56] Overall, examination of changes in $\mathrm{O}_{3} / \mathrm{CO}$ slopes has allowed more rigorous validation of the contribution of photochemistry to $\mathrm{O}_{3}$ changes in this $\mathrm{BB}$ plume since the model is able to reproduce the change from negative to positive slope. These results give confidence in the modeled photochemical contribution, and support the results presented in section 5.3. They confirm that significant $\mathrm{O}_{3}$ production took place during the plume transport, and that mixing had a large influence on CO concentrations.

\section{Possible Influence on $\mathrm{O}_{3}$ Levels in the European Lower Troposphere}

[57] The Lagrangian analyzes presented in the previous sections have shown that, for the particular case under investigation, there was a strong enhancement in $\mathrm{O}_{3}$ due to photochemistry after 5 days. Other studies have examined the influence of boreal forest fires during this period on the $\mathrm{O}_{3}$ budget over the North Atlantic. For example, Pfister et al. [2006] estimated a 10\% contribution to the tropospheric burden at the end of July 2004. Cooke et al. [2007] also estimated an $\mathrm{O}_{3}$ increase of $6 \mathrm{ppbv}$ in the boundary layer over the United Kingdom from 21 to 23 July 2004 due to $\mathrm{BB}$ emissions, but did not find any measurements to support their findings. However, global models often underestimate concentrations of pollutants in plumes due lack of horizontal and vertical resolution [Pfister et al., 2006; N. Bousserez et al., Evaluation of the MOCAGE chemistry transport model during the ICARTT/ITOP experiment, submitted to Journal of Geophysical Research, 2006], and may therefore underestimate the impact of $\mathrm{BB}$ events downwind over Europe. In this section, we extend the previous analysis further downwind in order to investigate the possible influence of the case examined here on $\mathrm{O}_{3}$ in the lower troposphere and the boundary layer over Europe. In the future, it would be interesting to examine other cases, and to compare these results with global models.

[58] For the period 23 to 26 July, we have examined data collected at surface sites to see whether there is evidence of transport of the BB plume studied here into the lower troposphere or boundary layer over Europe. FLEXPART simulations, run with $\mathrm{CO}$ BB tracers, showed that a large part of the plume was transported northward over Scandinavia with a significant fraction transported also over central Europe, and finer-scale filaments transported southward over France and the Mediterranean. Data was examined from Observatoire de Haute Provence (OHP) $\left(43^{\circ} 55 \mathrm{~N}\right.$, $\left.5^{\circ} 42 \mathrm{E}\right)$ in southern France where two $\mathrm{O}_{3}$ lidars and a backscatter lidar were operated during the ITOP campaign (see Ravetta et al. [2007] for details); Jungfraujoch $\left(46^{\circ} 55 \mathrm{~N}, 7^{\circ} 98 \mathrm{E}\right)$ at $3.6 \mathrm{~km}$ altitude in the Swiss Alps where measurements of many trace constituents including $\mathrm{CO}, \mathrm{O}_{3}$ and several hydrocarbons were made as well as meteorological variables, and aircraft profiles of $\mathrm{CO}$ and $\mathrm{O}_{3}$ from the Measurement of OZone, water vapor, carbon monoxide and nitrogen oxides by in-service AIrbus airCraft (MOZAIC) program [Nedelec et al., 2005]. Analysis using back trajectories identified the following features which appear to be linked to the Lagrangian case discussed in the previous sections (see Figure 9). Even if the different samplings are not directly linked in the Lagrangian sense, they were probably initially part of the same large plume.

[59] A MOZAIC flight over Paris on 23 July confirmed the presence of the layer seen by the DLR Falcon on the same day. Ozone lidar data collected at OHP on 24 July showed a layer at 3 to $4 \mathrm{~km}$ which was linked to the larger plume, if not exactly the same part of the plume sampled earlier by the Falcon. Measurements made during the period 24 to 26 July at Jungfraujoch are shown in Figure 10, together with results from the FLEXPART BB tracer simulations, when observed $\mathrm{CO}$ concentrations exceeded 200 ppbv. Trajectory analysis showed that on 24 July these enhancements were linked to a part of the larger plume when it was transported into the lower troposphere over Europe. Trajectories also suggest that this air mass continued to descend into the European boundary layer over eastern Europe and the Mediterranean.

[60] In order to evaluate the possible contribution of this $\mathrm{BB}$ plume to $\mathrm{O}_{3}$ levels over Europe the runs discussed in section 5 were run for a further 5 days from 24 to 28 July, and compared to data from OHP, Jungfraujoch and MOZAIC (Paris). The results for the 10 days period are shown in Figure 11. For the last 5 days of simulation, the aerosol OD was fixed at 0.13 and a mixing timescale of 5 days was used. FT background concentrations were used to constrain background concentrations as the plume was mainly transported in the FT, and no measurements were made in the proximity of the plume after the Falcon match. Simulated CO agrees reasonably well with the observations at Jungfraujoch when mixing is taken into account (pink shaded area) even if $\mathrm{O}_{3}$ concentrations at Jungfraujoch are slightly overestimated. It is also interesting to note that the modeled $\mathrm{O}_{3} / \mathrm{CO}$ slope continues to increase up to $11 \%$ until the plume enters a destruction regime when the slope starts to decrease. Observed and modeled $\mathrm{O}_{3} / \mathrm{CO}$ slopes at Jungfraujoch on 24 July are very similar, $7.5 \%$ and $7.7 \%$, respectively. Agreement with observed $\mathrm{O}_{3}$ at $\mathrm{OHP}$, where $\mathrm{O}_{3}$ levels were higher (around $80 \mathrm{ppbv}$ ), is less good supporting the idea that a different part of the plume was observed over southern France. The proximity of a tropospheric fold above the layer (also seen by the OHP lidar) suggests that additional mixing may have taken place with air masses of upper tropospheric origin. 

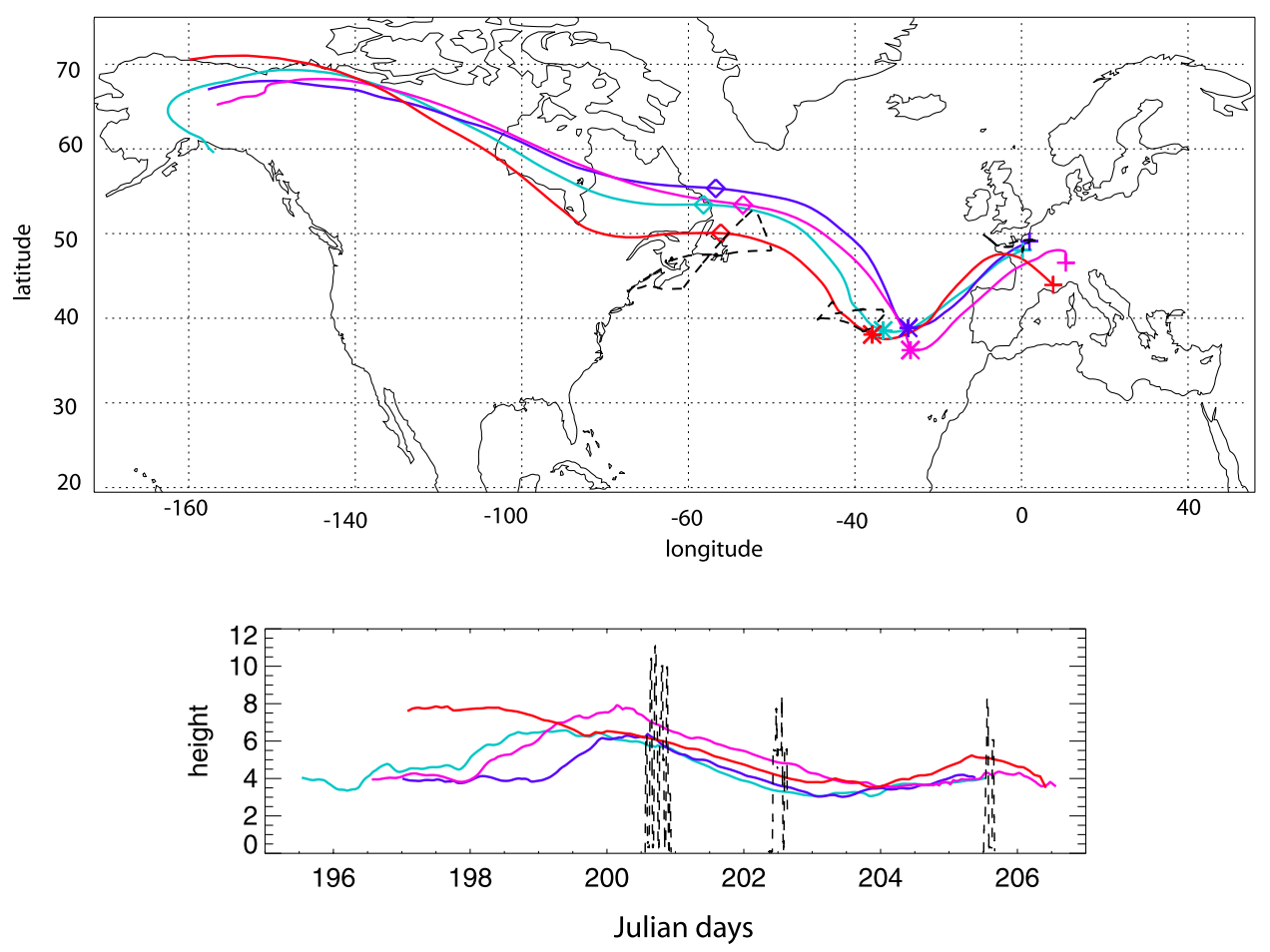

Figure 9. Ten-day backward trajectories from Jungfraujoch on 24 July (pink), OHP on 24 July (red), the Falcon BB plume sampling (light blue) and the MOZAIC BB plume sampling (blue) on 23 July. Crosses correspond to the initial trajectory release time, stars correspond to the BAe-146 mean match time (20 July, 1230 UT) and diamonds correspond to the DC8 mean match time (18 July, 1900 UT).

[61] Bearing in mind the caveats that this is not a truly Lagrangian analysis, and that mixing and aerosols parameters were less well constrained for the last 5 days of the plume evolution, it is still possible to use the results to examine the relative contributions of photochemistry and mixing to $\mathrm{O}_{3}$ levels in the plume after 10 days of transport. As noted above, results from the run including mixing give better agreement with the data further downwind, especially over Jungfraujoch, and suggest that the net change in $\mathrm{O}_{3}$ after 10 days was very small or even negative. However,
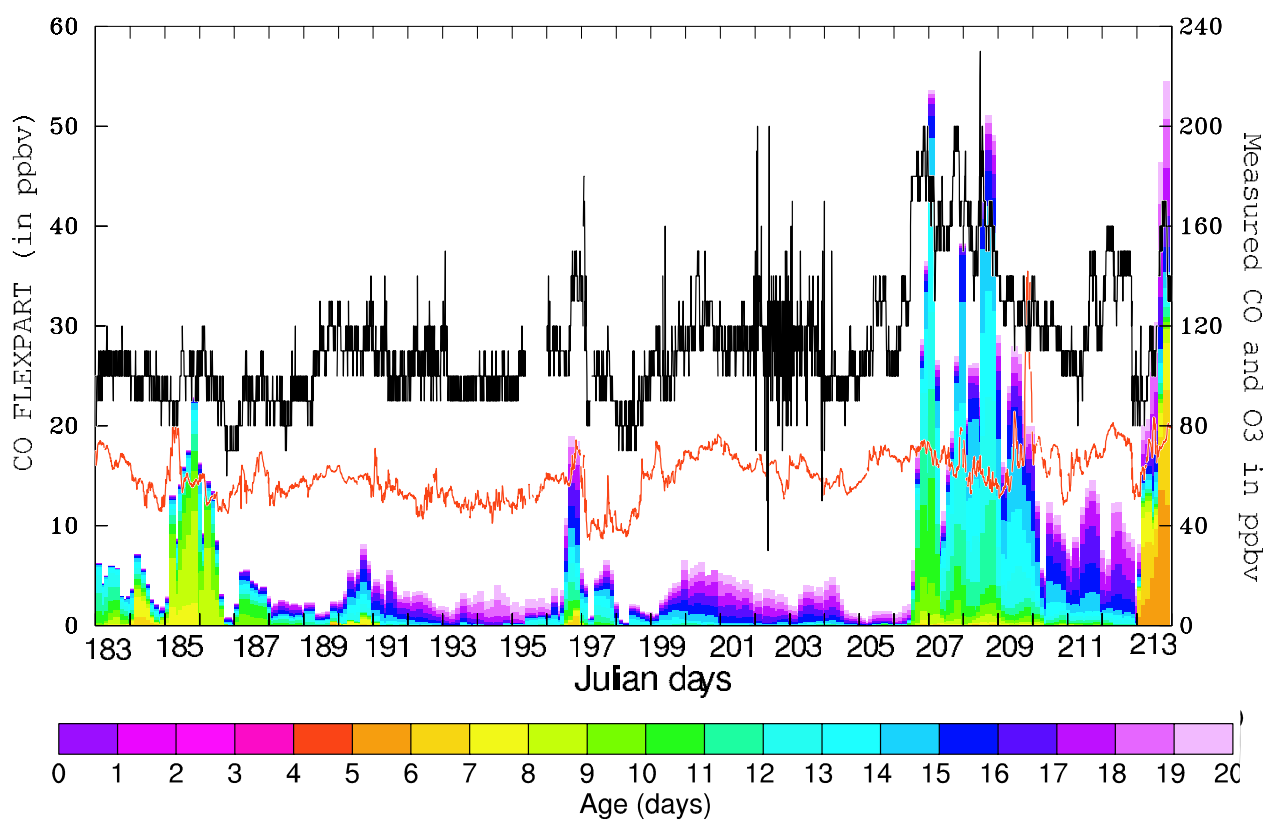

Figure 10. Measured $\mathrm{CO}$ mixing ratio (black line) and $\mathrm{O}_{3}$ mixing ratio (red line) at Jungfraujoch during July 2004, together with FLEXPART Alaskan fire CO tracers (ppbv above background) at Jungfraujoch, colored as a function of tracer age. BB plume influence is seen from 24 to 26 July (Julian days, 206 to 208). 

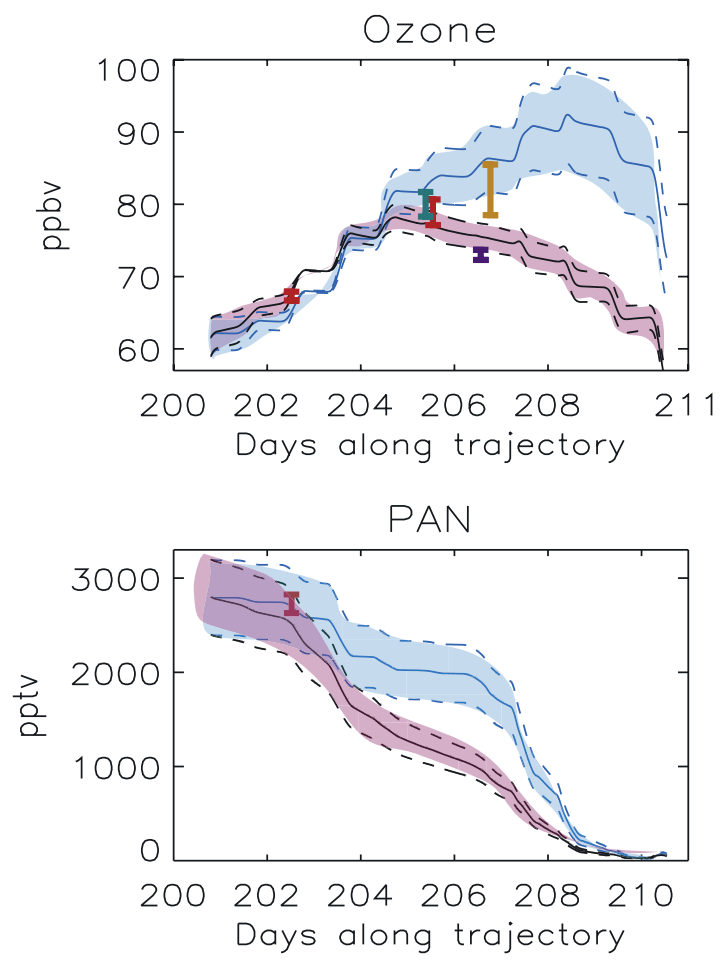
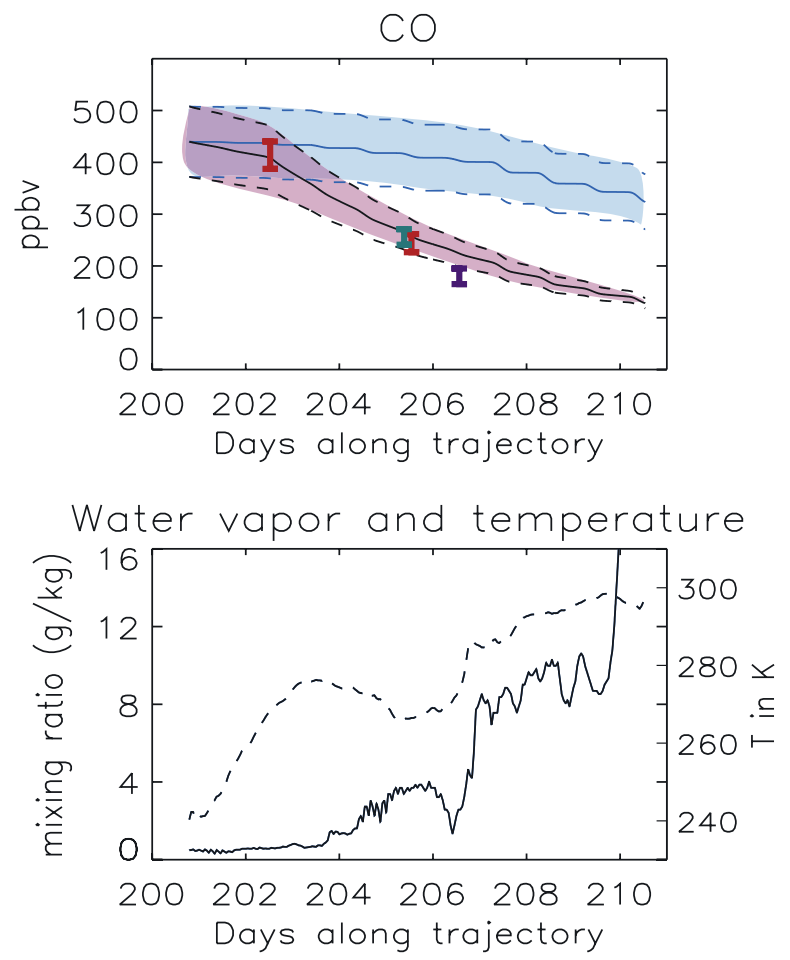

Figure 11. Simulated $\mathrm{O}_{3}, \mathrm{CO}$ and PAN mixing ratios, specific humidity (in $\mathrm{g} / \mathrm{kg}$, represented by the solid line) and temperature (in $\mathrm{K}$, represented by the dashed line) in the plume over 10 days with (pink) and without (blue) mixing for mean \pm std simulations. Measurements made by the BAe146 on 20 July (red), the Falcon (red) and MOZAIC aircraft (green) on 23 July, the OHP lidar (only $\mathrm{O}_{3}$, orange) on 24 July and at Jungfraujoch on 24 July (violet) are represented as vertical bars.

mixing processes mask the impact of photochemistry considerably by diluting the signature of the BB plume over Europe. Results from a chemistry-only simulation (blue shaded area) show that the plume was in a net $\mathrm{O}_{3}$ production regime during the first 8 days of simulation leading to an increase of 30 to $40 \mathrm{ppbv}$ over this period, primarily as a result of PAN decomposition. During the last 2 days there is net $\mathrm{O}_{3}$ destruction over Europe when PAN is almost completely decomposed because of elevated temperatures and water vapor has also increased. The net change in $\mathrm{O}_{3}$ in the chemistry-only simulation over the 10 day period is 8 to $12 \mathrm{pbbv}$.

[62] Despite the dilution effect on pollutant levels in the plume, it is clear that $\mathrm{BB}$ plumes can have an impact on $\mathrm{CO}$ and $\mathrm{O}_{3}$ levels in the European lower troposphere, and even the boundary layer since the data and model simulations show high levels of both species over Europe between 22 and 26 July. Several other BB plumes were also sampled over Europe during the ITOP campaign. For example, the Falcon sampled $\mathrm{BB}$ plumes several times with enhanced $\mathrm{CO}$ (up to $350 \mathrm{ppbv}$ ), $\mathrm{O}_{3}$ (up to $100 \mathrm{ppbv}$ ) and $\mathrm{NO}_{y}$ (up to $2500 \mathrm{pptv}$ ) including one low-level case on 26 July off the coast of France at $1.5 \mathrm{~km}$ when $\mathrm{CO}$ was $270 \mathrm{ppbv}$ and $\mathrm{O}_{3}$ was 95 ppbv. MOZAIC profiles collected during the campaign period also showed many plumes with enhanced $\mathrm{CO}$ (up to $300 \mathrm{ppbv}$ ) and $\mathrm{O}_{3}$ (up to $85 \mathrm{ppbv}$ ) over Paris, Frankfurt and Vienna between 3 and $7 \mathrm{~km}$ which are likely to be BB plumes given such high $\mathrm{CO}$ concentrations. All these plumes give different $\mathrm{O}_{3} / \mathrm{CO}$ slopes ranging from $4 \%$ to $40 \%$. This likely reflects their different histories in terms of temperature and humidity which, as shown previously, can have a large impact on net photochemical $\mathrm{O}_{3}$ production. This is particularly true for $\mathrm{BB}$ plumes which have high PAN loadings. These results show that caution is required when attributing $\mathrm{O}_{3}$ changes to photochemistry alone since mixing with other air masses can also have a significant impact. It also makes detection of $\mathrm{O}_{3}$ anomalies linked to long-range transport of pollutants into the European lower troposphere or even the boundary layer extremely difficult.

\section{Conclusions}

[63] A case of a BB plume transported from Alaska to Europe, has been analyzed using a Lagrangian approach. This plume was sampled 3 times by different aircraft during the IGAC Lagrangian 2K4 campaign (summer 2004) over northeast North America, the North Atlantic and Europe. Lagrangian match segments along the flight tracks were defined by Methven et al. [2006] using a combined trajectory/VOC fingerprint analysis. Measurements in the plume show an $\mathrm{O}_{3}$ increase of 17 ppbv over 5 days together with a significant decrease in $\mathrm{CO}$, and a change from negative to positive $\mathrm{O}_{3} / \mathrm{CO}$ correlations over the same time period.

[64] The CiTTyCAT model has been used to study the processes governing the chemical evolution of the plume, and in particular, changes in $\mathrm{O}_{3}$. The model was initialized with upwind measurements in the BB plume, and compared with downwind measurements. The influence of high aerosol loadings on photolysis rates in the plume was taken into account by combining in situ aerosol measurements in the BB plume and lidar measurements with a photolysis module 
(Fast-J), implemented in CiTTyCAT. The impact of BB aerosol on photolysis rates over the 5 days of simulation, was $-21 \%$ for $\mathrm{jNO}_{2}$ and $-22 \%$ for $\mathrm{jO}_{3}$ leading to a global reduction of photochemistry in the plume. $\mathrm{O}_{3}$ production was reduced by $18 \%$ and $\mathrm{O}_{3}$ destruction by $24 \%$ leading to less net $\mathrm{O}_{3}$ production in this case. Factors such as single scattering albedo, optical depth and phase function were found to be important. These results show that such BB aerosol effects on photochemistry can be important, and should be taken into account in chemical model simulations.

[65] Despite the slowing down of photochemistry in the plume due to BB aerosols, the model predicts that the plume was very chemically active. Net $\mathrm{O}_{3}$ production was estimated to be 22 ppbv over 5 days with a chemistry-only run. This large $\mathrm{O}_{3}$ production in the plume was driven by thermal decomposition of PAN which was very elevated in the plume, and made up $80 \%$ of $\mathrm{NO}_{y}$ during the upwind sampling by the DC8. Temperatures, which were low initially, warmed by more than $30 \mathrm{~K}$ along the plume pathway leading to this PAN decomposition. Low water vapor content (measured) in the plume also helped to maintain this high net $\mathrm{O}_{3}$ production.

[66] It was also shown that the chemistry-only simulation was not able to reproduce observed values of certain pollutants, especially $\mathrm{CO}$ and $\mathrm{NO}_{y}$, after 5 days, and that mixing/dilution of the plume must also have been important. In situ measurements collected in close proximity to the plume were used to constrain background concentrations, and mixing timescales were chosen to obtain the best agreement between modeled and observed $\mathrm{CO}$ in the plume in relation to the meteorological situation. The best results were obtained by using concentrations representative of a UT air mass during the first 2 days, and FT concentrations during the last 3 days with mixing timescales of 20 days and 5 days, respectively (giving an integrated mixing timescale of 6.25 days). With this mixing scenario, simulated $\mathrm{CO}, \mathrm{O}_{3}$, $\mathrm{NO}_{y}$ and $\mathrm{NO}$ levels were in the range of observations made in the plume after 2 and 5 days.

[67] Results using multiple model simulations were also used to test more rigorously the contribution of photochemistry to observed changes by comparing simulated and observed $\mathrm{O}_{3} / \mathrm{CO}$ slopes in the plume. The change from negative to positive correlation during transport across the North Atlantic was well simulated by the model runs even if the observed slopes were slightly underestimated. These results confirm that the large increase in $\mathrm{O}_{3}$ was mainly due to photochemistry. Extension of the model runs for a further 5 days over Europe showed that once the plume entered the lower troposphere, $\mathrm{O}_{3}$ destruction dominated. Dilution effects were also increasingly important, leading to only very small simulated net $\mathrm{O}_{3}$ changes after 10 days. These results are supported by comparison with available ground-based and aircraft data which showed evidence for this plume being transported into the lower troposphere over Europe.

[68] Overall, the influence of Alaskan BB plumes on $\mathrm{O}_{3}$ levels over Europe may have been particularly important in summer 2004, at least in the FT as shown by the different BB plume samplings by aircraft and ground based stations, and as suggested by global model simulations [Pfister et al., 2006; Cooke et al., 2007]. However, $\mathrm{O}_{3}$ changes in such plumes can vary significantly since they depend on the photochemical and physical history of each plume which, in turn, depends on PAN loading, temperature and water vapor evolution along the pathway as well as dilution effects. The results presented here show that it is important to distinguish between these different processes.

[69] Recent studies predict that boreal wildfires may increase in the future because of climate change [Stocks, 1998], and possibly increased direct human impact [Mollicone et al., 2006]. As forest fire plumes are likely to have high PAN loading because of the abundance of oxygenated volatile organic compounds [Singh et al., 1994; Fan et al., 1994], their ability to transport $\mathrm{O}_{3}$ on intercontinental scales is large, and their impact is likely to be important over the entire Northern Hemisphere.

[70] Acknowledgments. Elsa Real and Kathy Law acknowledge financial support from national programs (PNCA, PATOM) provided by INSU-CNRS and ADEME and also from Institut Pierre Simon Laplace (IPSL) and the Institut Geographique National (IGN) for hosting the DLR Falcon campaign at Creil, France. We would like to thank M. Haeffelin, C. Pietras and Y. Morille for making measurements using the IPSL-SIRTA aerosol lidar during the ITOP campaign and for subsequent analysis of the data. We also would like to thank the whole ICARTT team and, in particular, UK BAe-146 scientists (Lisa Whalley and Jim Hopkins for PAN and VOC data) and NASA DC8 scientists (Bill Brune (NO data), Ron Cohen $\left(\mathrm{NO}_{2}\right.$ data), Jack Dibb $\left(\mathrm{HNO}_{3}\right.$ data), Glen Diskin (water vapor), Vince Brackett and John Hair (aerosol data and aerosol optical depth retrievals). We also express our gratitude to NABEL-BUWAL in Switzerland for access to the chemical data from the Jungfraujoch site and Philippe Nedelec for provision of MOZAIC $\mathrm{O}_{3}$ and $\mathrm{CO}$ data.

\section{References}

Andreae, M. O., et al. (1988), Biomass-burning emissions and associated haze layers over Amazonia, J. Geophys. Res., 93, 1509-1527.

Andreae, M. O., B. E. Anderson, D. R. Blake, J. D. Bradshaw, J. E. Collins, G. L. Gregory, G. W. Sachse, and M. C. Shipham (1994), Influence of plumes from biomass burning on atmospheric chemistry over the equatorial and tropical South Atlantic during CITE3, J. Geophys. Res., 99, $12,793-12,808$.

Arnold, S. R., et al. (2007), Statistical inference of OH concentrations and air mass dilution rates from successive observations of nonmethane hydrocarbons in single air masses, J. Geophys. Res., doi:10.1029/ 2006JD007594, in press.

Cadet, B., V. Giraud, M. Haeffelin, P. Keckhut, A. Rechou, and S. Baldy (2005), Improved retrievals of cirrus cloud optical properties using a combination of lidar methods, Appl. Opt., 44(9), 1726-1734.

Cooke, P., et al. (2007), Forest fire plumes over the North Atlantic: p-TOMCAT model simulations with aircraft and satellite measurement from the ITOP/ICARTT campaign, J. Geophys. Res., doi:10.1029/ 2006JD007563, in press.

Crutzen, P. J., and M. O. Andreae (1990), Biomass burning in the tropics: Impact on atmospheric chemistry and biogeochemical cycles, Science, 250, 1669-1678.

Crutzen, P. J., L. E. Heidt, J. P. Krasnec, W. H. Pollock, and W. Seiler (1979), Biomass burning as a source of the atmospheric trace gases CO, $\mathrm{H}_{2}, \mathrm{~N}_{2} \mathrm{O}, \mathrm{NO}, \mathrm{CH}_{3} \mathrm{Cl}$ and COS, Nature, 282, 253-256.

Damoah, R., et al. (2006), A case study of pyro-convection using transport model and remote sensing data, Atmos. Chem. Phys., 6, 173-185.

Daum, P. H., L. Kleinman, D. G. Imre, L. Nunnermacker, Y. N. Lee, S. R. Springston, and L. Newman (2000), Analysis of the processing Nashville urban emissions on July 3 and July 18, J. Geophys. Res., 105, 91079119.

Duck, T. J., et al. (2007), Transport of forest fire emissions from Alaska to Nova Scotia during summer 2004, J. Geophys. Res., doi:10.1029/ 2006JD007716, in press

Duncan, B. N., I. Bey, M. Chin, L. J. Mickley, T. D. Fairlie, R. V. Martin, and H. Matsueda (2003), Indonesian wildfires of 1997: Impact on tropospheric chemistry, J. Geophys. Res., 108(D15), 4458, doi:10.1029/ 2002JD003195.

Evans, M. J., and D. Jacob (2005), Impact of new laboratory studies of $\mathrm{N}_{2} \mathrm{O}_{5}$ hydrolysis on global model budgets of tropospheric nitrogen oxides, ozone and OH, Geophys. Res. Lett., 32, L09813, doi:10.1029/ 2005GL022469.

Evans, M. J., et al. (2000), Evaluation of a Lagrangian box model using field measurements from EASE (Eastern Atlantic Summer Experiment) 1996, Atmos. Environ., 34, 3843-3863. 
Fan, S.-M., et al. (1994), Origin of tropospheric $\mathrm{NO}_{x}$ over subartic eastern Canada in summer, J. Geophys. Res., 99, 16,867-16,877.

Fehsenfeld, F. C., et al. (2006), International Consortium for Atmospheric Research on Transport and Transformation (ICARTT): North America to Europe-Overview of the 2004 summer field study, J. Geophys. Res., 111, D23S01, doi:10.1029/2006JD007829.

Fiebig, M., A. Petzold, U. Wandinger, M. Wendisch, C. Kiemle, A. Stifter, M. Ebert, T. Rother, and U. Leiterer (2002), Optical closure for an aerosol column: Method, accuracy, and inferable properties applied to a biomassburning aerosol and its radiative forcing, J. Geophys. Res., 107(D21), 8130, doi:10.1029/2000JD000192.

Forster, C., et al. (2001), Transport of boreal forest fire emissions from Canada to Europe, J. Geophys. Res., 106, 22,887-22,906.

Galanter, M., H. Levy II, and G. R. Carmichael (2000), Impact of biomass burning on tropospheric $\mathrm{CO}, \mathrm{NO}_{x}$ and $\mathrm{O}_{3}, J$. Geophys. Res., 105(D5), $6633-6654$

Goode, J., R. J. Yokelson, D. E. Ward, R. E. Babbit, M. A. Davies, and W. M. Hao (2000), Measurements of excess $\mathrm{O}_{3}, \mathrm{CO}_{2}, \mathrm{CH}_{4}, \mathrm{C}_{2} \mathrm{H}_{2}, \mathrm{HCN}$, $\mathrm{NO}, \mathrm{NH}_{3}, \mathrm{HCOOH}, \mathrm{CH}_{3} \mathrm{COOH}, \mathrm{HCHO}$ and $\mathrm{CH}_{3} \mathrm{OH}$ in 1997 Alaskan biomass burning plumes by airborne Fourier transform spectroscopy (AFTIR), J. Geophys. Res., 105, 22,147-22,166.

Haeffelin, M., et al. (2005), SIRTA, a ground-based atmospheric observatory for cloud and aerosol research, Ann. Geophys., 23, 253-275.

Harriss, R. C., et al. (1992), The Artic Boundary Layer Expedition (ABLE3A): July-August 1998, J. Geophys. Res., 97, 16,383-16,394.

Hobbs, P. V., P. Sinha, R. J. Yokelson, T. J. Christian, D. R. Blake, S. Gao, T. W. Kirchstetter, T. Novakov, and P. Pilewskie (2003), Evolution of gases and particles from a savanna fires in South Africa, J. Geophys. Res., 108(D13), 8485, doi:10.1029/2002JD002352.

Hough, A. (1988), The calculation of photolysis rates for use in global troposheric modeling studies, technical report, Energy Res. Estab., Her Majesty's Stn. Off., London.

Jacob, D. J., J. A. Logan, and P. P. Murti (1999), Effect of rising Asian emissions on surface ozone in the United States, Geophys. Res. Lett., 26 , $2175-2178$

Kondo, Y., et al. (2004), Impacts of biomass burning in Southeast Asia on ozone and reactive nitrogen over the western Pacific in spring, J. Geophys. Res., 109, D15S12, doi:10.1029/2003JD004203.

Kotamarthi, V. R., P. V. Doskey, S. R. Springston, J. S. Gaffnay, and N. A. Marley (2006), Modeling of trace gases from the 1998 north central Mexico forest fire smoke plume, as measured over Phoenix, Atmos. Chem. Phys., 6, 3227-3264.

Mauzerall, D. L., et al. (1998), Photochemistry in biomass burning plumes and implications for tropospheric ozone over the tropical South Atlantic, J. Geophys. Res., 103, 8401-8423.

McKeen, S. A., G. Wotawa, D. D. Parrish, J. S. Holloway, M. P. Buhr, G. Hubler, F. C. Fehsenfeld, and J. F. Meagher (2002), Ozone production from Canadian wildfires during June and July of 1995, J. Geophys. Res. 107(D14), 4192, doi:10.1029/2001JD000697.

Methven, J., et al. (2006), Establishing Lagrangian connections between observations within air masses crossing the Atlantic during the International Consortium for Atmospheric Research on Transport and Transformation experiment, J. Geophys. Res., 111, D23S62, doi:10.1029/ 2006JD007540.

Mishchenko, M. I., I. Goegdzhayev, B. Cairns, W. B. Rossow, and A. A. Lacis (1999), Aerosol retrievals over the ocean by use of channels 1 and 2 AVHRR data: Sensitivity analysis and preliminary results, Appl. Opt., 38, $7325-7341$.

Mollicone, D., H. Eva, and F. Achard (2006), Human role in Russian wild fires, Nature, 440, 436-437.

Morris, G. A., et al. (2006), Alaskan and Canadian forest fires exacerbate ozone pollution over Houston, Texas, on 19 and 20 July 2004, J. Geophys. Res., 111, D24S03, doi:10.1029/2006JD007090.

Nedelec, P., V. Thouret, J. Brioude, B. Sauvage, J.-P. Cammas, and A. Stohl (2005), Extreme CO concentrations in the upper troposphere over northeast Asia in June 2003 from the in situ MOZAIC aircraft data, Geophys. Res. Lett., 32, L14807, doi:10.1029/2005GL023141.

Pak, B. C., et al. (2003), Measurements of biomass burning influences in the troposphere over southeast Australia during the SAFARI 2000 dry season campaign, J. Geophys. Res., 108(D13), 8480, doi:10.1029/2002JD002343.

Petzold, A., et al. (2007), Perturbation of the European free troposphere aerosol by North Amercian forest fire smoke plumes during the ICARTTITOP study in summer 2004, Atmos. Chem. Phys, in press.

Pfister, G., P. G. Hess, L. K. Emmons, J.-F. Lamarque, C. Wiedinmyer, D. P. Edwards, G. Ptron, J. C. Gille, and G. W. Sachse (2005), Quantifying CO emissions from the 2004 Alaskan wildfires using MOPITT CO data, Geophys. Res. Lett., 32, L11809, doi:10.1029/2005GL022995.

Pfister, G. G., et al. (2006), Ozone production from the 2004 North American boreal fires, J. Geophys. Res., 111, D24S07, doi:10.1029/ 2006JD007695.
Ravetta, F., G. Ancellet, and A. Colette (2007), Long-range transport and tropospheric ozone variability in the western Mediterranean region during ITOP-2004, J. Geophys. Res., doi:10.1029/2006JD007724, in press.

Reid, J. S., R. Koppmann, T. F. Eck, and D. P. Eleuterio (2004), A review of biomass burning emissions part II: Intensive physical properties of biomass burning particles, Atmos. Chem. Phys., 4, 5135-5200.

Reid, J. S., T. F. Eck, S. A. Christopher, R. Koppmann, O. Dubovik, D. P. Eleuterio, B. N. Holben, E. A. Reid, and J. Zhang (2005), A review of biomass burning emissions part III: Intensive optical properties of biomass burning particles, Atmos. Chem. Phys., 5, 827-849.

Reuder, J., and H. Schwander (1999), Aerosol effects on UV radiation in nonurban regions, J. Geophys. Res., 104, 4065-4077.

Rex, M., et al. (1998), In situ measurements of stratospheric ozone depletion rates in the Artic winter 1991/1992: A Lagrangian approach, J. Geophys. Res., 103, 5843-5853.

Singh, H. B., D. O'Hara, D. Herlth, W. Sachse, D. R. Blake, J. D. Bradshaw, M. Kanakidou, and P. J. Crutzen (1994), Acetone in the atmosphere: Distribution, sources and sinks, J. Geophys. Res., 99, 1805-1819.

Sloane, C. S. (1984), Optical properties of aerosols of mixed composition, Atmos. Environ., 18, 871-878.

Stith, J. L., L. F. Radke, and P. V. Hobbs (1981), Particles emissions and the production of ozone and nitrogen oxides from the burning of forest slash, Atmos. Environ., 15, 73-82.

Stocks, B. (1998), Climate change and forest fire potential in Russian and Canadian boreal forests, Clim. Change, 38, 1-13.

Stohl, A. (1998), Computation, accuracy and applications of trajectoriesA review and bibliography, Atmos. Environ., 32, 947-966.

Stohl, A. (2001), A 1-year Lagrangian "climatology" of airstreams in the Northern Hemisphere troposphere and lowermost stratosphere, J. Geophys. Res., 106, 7263-7279.

Stohl, A., G. Wotawa, P. Seibert, and H. Kromp-Kolb (1995), Interpolation errors in wind fields as a funcion of spatial and temporal resolution and their impact on different types of kinematic trajectories, J. Appl. Meteorol., 34, 2149-2165.

Stohl, A., et al. (2006), Pan-Arctic enhancements of light absorbing aerosol concentrations due to North American boreal forest fires during summer 2004, J. Geophys. Res., 111, D22214, doi:10.1029/2006JD007216.

Tang, Y., et al. (2003), Influences of biomass burning during the Transport and Chemical Evolution Over the Pacific (TRACE-P) experiment identified by the regional chemical transport model, J. Geophys. Res., 108(D21), 8824, doi:10.1029/2002JD003110.

Trentmann, J., M. O. Andreae, H.-F. Graf, P. V. Hobbs, R. D. Ottmar, and T. Trautmann (2002), Simulation of a biomass-burning plume: Comparison of model results with observations, J. Geophys. Res., 107(D2), 4013, doi:10.1029/2001JD000410.

Trentmann, J., M. O. Andreae, and H.-F. Graf (2003), Chemical processes in a young biomass-burning plume, J. Geophys. Res., 108(D22), 4705, doi:10.1029/2003JD003732.

Turquety, S., et al. (2007), Inventory of boreal fire emissions for North America in 2004: Importance of peat burning and pyroconvection injection, J. Geophys. Res., 112, D12S03, doi:10.1029/2006JD007281.

Val Martín, M., R. E. Honrath, R. C. Owen, G. Pfister, P. Fialho, and F. Barata (2006), Significant enhancements of nitrogen oxides, black carbon, and ozone in the North Atlantic lower free troposphere resulting from North American boreal wildfires, J. Geophys. Res., 111, D23S60, doi:10.1029/2006JD007530.

Volz-Thomas, A., and B. Kolahgar (2000), On the budget of hydroxyl radicals at Schauinsland during the Schauinsland Ozone Precursors Experiment (SLOPE96), J. Geophys. Res., 105, 1611-1622.

Wild, O., and H. Akimoto (2001), Intercontinental transport of ozone and its precursors in a three-dimensional global CTM, J. Geophys. Res., 106, 27,729-27,744.

Wild, O., K. S. Law, D. S. McKenna, B. J. Bandy, S. A. Penkett, and J. A. Pyle (1996), Photochemical trajectory modeling studies of the North Atlantic region during August 1993, J. Geophys. Res., 101, 29,26929,288 .

Wild, O., X. Zhu, and M. J. Prather (2000), Fast-J: Accurate simulation of in- and below-cloud photolysis in tropopsheric chemical models, J. Atmos. Chem., 37, 245-282.

Wotawa, G., and M. Trainer (2000), The influence of Canadian forest fires on pollutant concentrations in the United States, Science, 288, 324-328.

S. Arnold, School of Earth and Environment, University of Leeds, Leeds LS2 9JT, UK. (sra@env.leeds.ac.uk)

M. Avery, E. Browell, R. Ferrare, and G. Sachse, NASA Langley Research Center, Mail Stop 401B, 5 North Dryden Street, Hampton, VA 23681-2199, USA. (m.a.avery@larc.nasa.gov; e.v.browell@larc.nasa.gov; r.a.ferrare@larc.nasa.gov; g.w.sachse@larc.nasa.gov) 
D. Blake, Department of Chemistry, 570 Rowland Hall, University of California, Irvine, CA 92697-2025, USA. (dblake@orion.oac.uci.edu)

M. Fiebig, H. Huntrieser, A. Petzold, A. Roiger, H. Schlager, and B. Weinzierl, Institut für Physik der Atmosphäre, Deutsches Zentrum für Luft- und Raumfahrt, D-82230 Wessling, Germany. (markus.fiebig@dlr.de; heidi.huntrieser@dlr.de; anke-elisabeth.roiger@dlr.de; hans.schlager@dlr.de; bernadett.weinzierl@dlr.de)

K. Law and E. Real, Service d'Aéronomie du CNRS, 3ème étage, Tour 45-46, 4 Place Jussieu, F-75005 Paris, France. (kathy.law@aero.jussieu.fr; elsa.real@aero.jussieu.fr)
J. Methven, Department of Meteorology, University of Reading, P.O. Box 243, Reading RG6 6BB, UK. (j.methven@reading.ac.uk)

D. Stewart, School of Environmental Science, University of East Anglia, Norwich NR47TJ, UK. (d.stewart@uea.ac.uk)

A. Stohl, Norwegian Institute for Air Research, Instituttveien 18, N-2027 Kjeller, Norway. (ast@nilu.no)

O. Wild, Centre for Atmospheric Science, Department of Chemistry, University of Cambridge, Lensfield Road, Cambridge CB21EW, UK. (oliver.wild@atm.ch.cam.ac.uk) 